\title{
A wear rate model incorporating inflationary cost of agro-waste filled composites for brake pad applications to lower composite cost
}

\author{
Oluwaseyi Ayodele Ajibade ${ }^{1}$. Johnson Olumuyiwa Agunsoye ${ }^{1}$. Sunday Ayoola Oke ${ }^{2}$ (i)
}

Received: 27 May 2020 / Accepted: 21 December 2020 / Published online: 7 January 2021

(C) The Author(s) 2020 OPEN

\begin{abstract}
Wear rate appraisals are currently indispensable on agro-waste filled composites for brake pads as they predict the expected lifespan of the materials. However, existing wear rate models are inaccurate as predictions omit the inflationary cost of the materials. In this paper, the idea is to account for the inflationary cost of the materials and adjust that into a pseudo wear rate model. The wear rate of agro-waste fillers in an organic matrix to create brake pads under dry sliding wear experiments was considered. Five composite specimens were fabricated in cylindrical specimen height of $14.5 \mathrm{~mm}$ and varying diameters of $8,10,12$ and $15.5 \mathrm{~mm}$ and the material wear loss was measured. The 8,10 and $12 \mathrm{~mm}$ diameter specimens revealed that the composite with the best and worst wear resistance were the wear rates of $0.6,1.4$, $1.73 \mathrm{~mm}^{3} / \mathrm{Nm}$, and $3.07,3.54,4.19 \mathrm{~mm}^{3} / \mathrm{Nm}$, respectively. The $15.5 \mathrm{~mm}$ diameter specimen showed lower wear rates of 2.13 and 2.14 and $1.56 \mathrm{~mm}^{3} / \mathrm{Nm}$ than commercial brake pad's $2.58 \mathrm{~mm}^{3} / \mathrm{Nm}$. The pseudo wear rate model predicts the impact of the independent variable i.e. inflationary cost, opportunity cost, time, and sample size. The utility of this effort is to assist the composite manufacturers to take cost-effective decisions and design optimisation can be accomplished to lower the cost of composite products.
\end{abstract}

Keywords Wear rate $\cdot$ Wear $\cdot$ Economics of wear $\cdot$ Agricultural wastes $\cdot$ Composites

$\begin{array}{ll}\text { Abbreviations } \\ \text { SD } & \text { Sliding distance } \\ \text { IF } & \text { Inflationary factor } \\ \text { WR } & \text { Wear rate } \\ \text { COF } & \text { Coefficient of friction } \\ \text { OC } & \text { Opportunity cost } \\ \text { SWR } & \text { Specific wear rate } \\ \text { AL } & \text { Applied load }\end{array}$

\section{Introduction}

The dominant practice of appraising the wear rate of composite materials concerns hardness, particle agglomeration, volume of reinforcement particles and the fracture toughness of composites [1-3]. Unfortunately, the prevailing wear rate model of composite materials fails to account for the inflationary cost of composite materials [4]. But this propels cost-effective decisions and design optimization and consequently, to lower the cost of composite products [5]. This leads to an underestimation of real cost and may lead to gross inadequacy in wear rate estimations of composite materials [6-8]. But incorporating inflationary costs will offer superior and more practical picture [6]. Nowadays, this concern is more compelling than before to implement in the industry [9-11] because of the incredibly impressive accuracy expected from initiating inflationary costs into wear rate estimations in composite material. In this paper, a new wear rate model is proposed to account for the inflationary cost of composite materials and adjust that in a pseudo wear rate model.

Sunday Ayoola Oke, sa_oke@yahoo.com | 'Department of Metallurgical and Materials Engineering, University of Lagos, Lagos, Nigeria. ${ }^{2}$ Department of Mechanical Engineering, University of Lagos, Lagos, Nigeria. 
Consequently, this research applies the theory of inflation [6-8] to appraise and update the current knowledge on wear rate. The theory of inflation is a theoretical base which offers a method to appraise the inflationary cost of composite materials and adjust to a wear rate model by incorporating price changes. This research is substantial as it offers a structure to establish the important deficiency of inflationary costs in wear rate estimations of composite materials. Furthermore, it offers substantial details to composite researchers concerning the basic constituents of an inflationary based wear rate model and the necessary appraisal measures. Moreover, by exploiting and identifying the problem that is unattended to and weakness within the inflationary-based wear rate model domain stimulates future investigations,

This research contributes to the wear rate assessment literature by:

- highlighting assessment parameters and characteristics unclear in earlier wear rate research that could associate with enlarging the comprehension of researchers on the assessment parameters and scheme of appraisal;

- implementing the theory of inflation that can offer new reasoning and enhancement to the present ideas in appraising wear rate

- establishing research flaws of wear rate to properly position novel research pursuits

The next section details the literature survey, which widely scanned related references in the field. The methodology adopted for modelling the wear rate is discussed in Sect. 3. Section 4 highlights the results and the inferences from the study. Section 5 offers concluding remarks and ends the paper.

\section{Literature review}

In this section, a review is presented on brake pads in composites reinforced with agro-waste [12-14], single [15, 16], dual/multiple fillers [17]. First, an introduction to the brake pad is made $[18,19]$. Brake pads are heat and energyabsorbing media attached to the discs calipers, triggered to action by a hydraulic scheme in a squeezing action on the brake pads to a rotor, thus converting kinetic into heat energy in an automobile [20,21]. The brake pad medium, a most significant part of the automobiles braking scheme, consists of materials originally developed from organic basis (asbestos and carbon, for instance), tightly held by an effective resin [22-24]. In many brake pads, braking is instigated after a pedal is slowed down within the automobile. The squeezing action produces friction which is connected into heat that attacks the brake pads as well as the rotor [25-27]. The friction generated finally compels the automobile to stop $[28,29]$.

\subsection{Brake pads with agro-fillers}

Fu et al. [30] prepared brake pad composite from natural materials and metals to study the influence of both compositions of treated flax fibres and frictional temperature on frictional parameters (wear rate, frictional coefficient). Maleque et al. [15] reinforced aluminium matrix with different degrees of coconut fibre contents $(0,5,10$, and 15 volume ratios) using the powder metallurgy method. Elevated density, higher compressive strength, and lower porosity of the 5 and $10 \%$ coconut fibre reinforced composite specimens were obtained. Sugözü et al. [31] experimented with ulexite and combined it with cashew to make brake pads. The results revealed that the composite exerts substantial influences on its functional strength and fade resistance. Öktem et al. [32] produced composites with 3.5 and $7 \%$ contents of hazenut and walnut dust and noted that competing friction-wear test results with the commercial-grade brake pad. Rajmohan et al. [33] formed coconut shells, sugarcane and $\mathrm{SiC}$ powder brake pad composite and obtained the wear rate that ranged from $3.11 \times 10^{-6}$ to $4.13 \times 10^{-6} \mathrm{mg} / \mathrm{m}$. Akıncıoğlu et al. [34] produced two groups of brake pads: one originating from boron oxide powder $(6 \%)$ and the other arising from hazenut shell powder (7\%) and confirmed that the wear test yielded results comparable with commercial brake pads.

\subsection{Brake pads with single-fillers}

Aigbodion et al. [14] studied the bagasse reinforced composite for brake pads. The average wear of $4.20 \mathrm{mg} / \mathrm{m}$ for the composite was obtained. Olumodeji [35] established the wear resistance of powdered coconut shells and palm kernel shells reinforced latex composites with cement binder. The wear volume for an hour was $1.17 \mathrm{gm}$ and $2 \mathrm{gm}$ for the palm kernel pad and coconut pad, respectively. Ademoh and Olabisi [36] produced maize husk filled epoxy composited and declared that the optimum abrasion resistance of $4.47 \times 10-6 \mathrm{~g} / \mathrm{m}$ was obtained. Idris et al. [18] developed banana peel waste composite while using phenolic resin binder. The outcome reveals that wear rate reduced with the growth in wt $\%$ of the resin. Olabisi et al. [37] analysed the wear rate for the pulverized cocoa beans shell epoxy composite and obtained the wear rate of $3.934 \mathrm{mg} / \mathrm{m}$. Yawas et al. [38] studied the wear rate of periwinkle shell filled composite and concluded that the wear rate reduced as the corresponding powder size reduced. Ahmed et al. [39] produced brake pads using watermelon peels and revealed that $25 \mathrm{wt} \%$ preparation 
(resin) matched the commercial counterpart. Achebe et al. [40] produced palm kernel filled epoxy composite and reported the abrasion resistance of $1.67 \mathrm{mg} / \mathrm{m}$. The wear resistance enhanced as the palm kernel filler content increased. Akıncıoğlu et al. [41] studied the influence of braking performance on walnut shell powder composite using two classes of samples ( 3.5 and $7 \%$ walnut shell dust). A positive influence of the walnut shell dust composite on the frictional coefficient was established.

\subsection{Brake pads with dual/multiple-fillers}

Adeyemi et al. [42] intermixed three fillers (cocoa beans shell, palm kernel shells and maize husks) with an epoxy binder to obtain a composite subjected to the test of abrasion resistance. It was found that abrasion resistance reduced when the epoxy wt $\%$ increased in the preparation. Masturi et al. [43] produced organic brake canvas from two organic materials (durian fruit skin and teak leaves) reduced to powder with polyester resin and magnesium oxide additive. The wear resistance result obtained was close to the national standard by the Indonesian government. Uzochukwu et al. [44] developed brake pads with intermixed particles of cow-horn and periwinkle shells in epoxy resin and reported on their tribological characteristics. They revealed wear rates of $3.56 \times 10^{-4} \mathrm{~g} / \mathrm{m}$ and $3.7 \times 10^{-4} \mathrm{~g} / \mathrm{m}$ for composites containing $26 \%$ cow-horn/ periwinkle shells, $60 \%$ epoxy resin plus hardener and the other containing $32 \%$ cow-horn/periwinkle shells and $54 \%$ epoxy resin plus hardener, respectively.

\subsection{Wear mechanisms and testing machines}

The scientific literature framework on the types of wear mechanisms of composite materials and the testing machines used to obtain wear results are briefly mentioned. The wear mechanism phenomenon is best understood by analysing the complicated transformation during friction. The wear mechanisms discussed in the composite literature are mainly corrosive [45], abrasive [46, 47], fatigue [48], impact, adhesive and erosive [49]. Since the focus of this paper is on brake pads which fit into the automobile sector, alternatives to the DIN abrasion tester used in this work are briefly mentioned. Kumar [50] presented a wear testing machine capable to evaluate composites subjected to rolling and sliding wear. The design presented by Allebert et al. [51] tackles drum-like objects.

The review of the literature concluded in this paper exposes interesting research gaps as follows:

1. Attaining robust appraisal concerning wear rate of composites has been the key element of discussions in modelling and experimental reports. Quantified parameters of frictional coefficient, volume fractions of reinforcements and the effects of lubricants are very crucial in wear rate estimations. However, the economic aspects that echo an understanding of the real values of wear rate were not considered in the literature.

2. The mathematical models using the regression analysis and the Archard model are broadly elaborated in the literature. Neither the earlier nor the later model has sought the incorporation of the cost elements. But the real values of wear rate may be challenging to obtain in a practical sense without this perspective. Moreso, the regulatory environment on manufacturing industries call for sustainability, which may be costdriven. The inflationary cost viewpoint is henceforth a promising research aspect of wear rate modeling, experimentation and analysis.

3. A wide range of research on wear rate has been conducted, from polymer composites to aluminium metal matrix composites.

4. Studies have been experimental in nature as well as mathematical modelling of parameters as regression functions. The experiments include thermo-mechanical loading. Scanning electron microscopy was also used.

5. The production method has been mainly the stir casting method.

6. Interests of researchers were in hybridizing materials for enhanced wear rate but the metal matrix composites have been the major aspect of that attention.

7. Active research has been in the area of material coating where resistance to wear is highly desirable.

8. Studies have extensively exploited reinforcing metals with $\mathrm{TiB}$ and $\mathrm{TiC}$, and $\mathrm{TiB}_{2}$.

9. The theme of brake pads with agro-waste and single fillers have been extensively studied. However, extremely less research has been conducted on the theme of brake pads with dual/multiple fillers

From the research gaps indicated previously, it is implicit that incomplete attempts were made concerning the wear rate evaluation of agro-waste filled organic composites in brake pad applications. Furthermore, exceedingly negligible research was conducted in particular formulations involving the mixtures of particulate orange peels, coconut shells, eggshells, palm kernel shells and periwinkle shells. Subjected to some chosen parameters. Moreover, studies have been conducted with restrictions to the technical tribological parameters of hardness, wear volume, normal load and sliding distance to obtain enhanced wear rate. However, negligible research efforts were invested in the economic dimensions, viz. inflationary cost of composite materials. Consequently, in this 
paper, the researchers made an effort to account for the inflationary cost of agro-waste filler organic composites and adjusted that into a pseudo wear rate model. The material used finds great utility in brake pad development.

\section{Methodology}

\subsection{Materials}

The primary matrix used in this investigation is Epoxy resin of LY 556 type and it was cured at room temperature by the addition of amine hardener HY 951 which served as a secondary matrix. Orange peels, coconut, periwinkle, palm kernel shells were collected from local retailers in Oyingbo and Akoka market areas of Lagos, Nigeria while eggshells were obtained majorly from local fast-food chains in the aforementioned areas. The orange peels were sun-dried to remove moisture, while all the materials were cleaned to remove dirt and other impurities. The different materials were pulverized before milling into particulate forms. Each of the sieved particles was passed through a British Standard test sieve (Wykeham Farrance) with the use of an electric auto shaker for a minimum of $15 \mathrm{~min}$ to obtain $75 \mu \mathrm{m}$ particle size.

\subsection{Specimen preparation}

A $75 \mu \mathrm{m}$ particle size of dried orange peels, coconut, periwinkle, palm kernel and eggshells were combined according to different formulations in steps of 5 to obtain 25 weight percentage of total epoxy. Epoxy resin and amine hardener were combined in a ratio 1:0.5 by weight into a homogenous whole by careful mixing. Each of the reinforcement formulations was added to the epoxy resin and the mixture was stirred continuously for 5 min until homogeneity was attained. The composite material was poured into a prepared could be coated with a PVC release agent to ensure ease of removal of the composite. The mould was held securely with the use of G-clamps. The composites were allowed to cure at room temperature for $24 \mathrm{~h}$. They were further post-cured in an electric oven at $100{ }^{\circ} \mathrm{C}$ for $4 \mathrm{~h}$ to improve the mechanical properties of the composites. Figure 1 a shows the research scheme outlining the remaining part of the work.

In the present work, five different formulations and a control formulation, which is examples from the open market, for commercial usage is embarked upon and employed in our experimentation. From the family of formulations, only one sample is used based on directions from previous experimentation that specifically singled out the best samples according to the highest tensile values, and the corresponding specifications of samples are chosen. The samples chosen based on maximum tensile values are as follows (Table 1): The formulations in Table 1 represent the best among the variant formulations that combine particulates from the related organic materials. Before the commencement of the experiment, a literature study was made to discover the common weight percentages by the composition of organic materials in the domain of research. It was found out that several authors have different choices for the weight composition percentages. While some authors used $25 \mathrm{wt} \%$ for the organic materials others used $30 \mathrm{wt} \%$ and extremely less number of authors used $40 w t \%$. However, to avoid fabricating a brittle composite it was thought that making the composition of the fillers above $25 \mathrm{wt} \%$ may not offer the best result. So the upper boundary of any two mixed organic materials used in the work was limited to $25 \mathrm{wt} \%$. So extensive tests were conducted to vary the percentages of any two combinations, which sums up to $25 \mathrm{wt} \%$. For instance, in formulation 1, the wt $\%$ of OP and CSP must be $25 \mathrm{wt} \%$. This means that we have the options of $5 \mathrm{wt} \%$ of OP and $20 w t \%$ of CSP, $10 w t \%$ of OP and $15 w t \%$ of CSP, $5 w t \%$ of CSP and $20 w t \%$ of OP, $10 w t \%$ of CSP and $15 w t \%$ of OP, $20 w t \%$ of CSP and $5 w t \%$ of OP. All these options were tested for hardness and the option with the highest hardness was obtained as $10 \mathrm{wt} \%$ of OP and $15 \mathrm{wt} \%$ of CSP and chosen as the representative for formulation 1 in Table 1. Other formulations 2 to 5 were combined and similarly tested for hardness and the final results are displayed in Table 1.

The samples' specifications are known by mass $(\mathrm{g})$, height $(\mathrm{cm})$, radius $(\mathrm{cm})$, volume $\left(\mathrm{cm}^{3}\right)$ and density $\left(\mathrm{g} / \mathrm{cm}^{3}\right)$ and the ranges are specified in Table 2.

\subsection{Measurement of wear and coefficient of friction (COF)}

Tests on dry sliding wear were conducted using a DIN abrasion tester as per ASTM G 99 standard for polymeric materials. The tip of the specimen was held securely in a sample holder against an abrasive paper of size P $60 \mathrm{com}$ mercial grade attached with the aid of an adhesive to a cylindrical disc of $150 \mathrm{~mm}$ diameter. Other parameters like applied load, time of rotation were fixed manually in the course of the experiment. The quantities used in the measurement of the wear process were obtained as follows:

$S_{S}(m / s)=\frac{\pi D N}{60,000}$

where $D$ is the diameter of wear track in $\mathrm{mm}, N$ is the speed in rpm, and $T$ is the duration of the test in seconds, $\mathrm{s}$ 
a

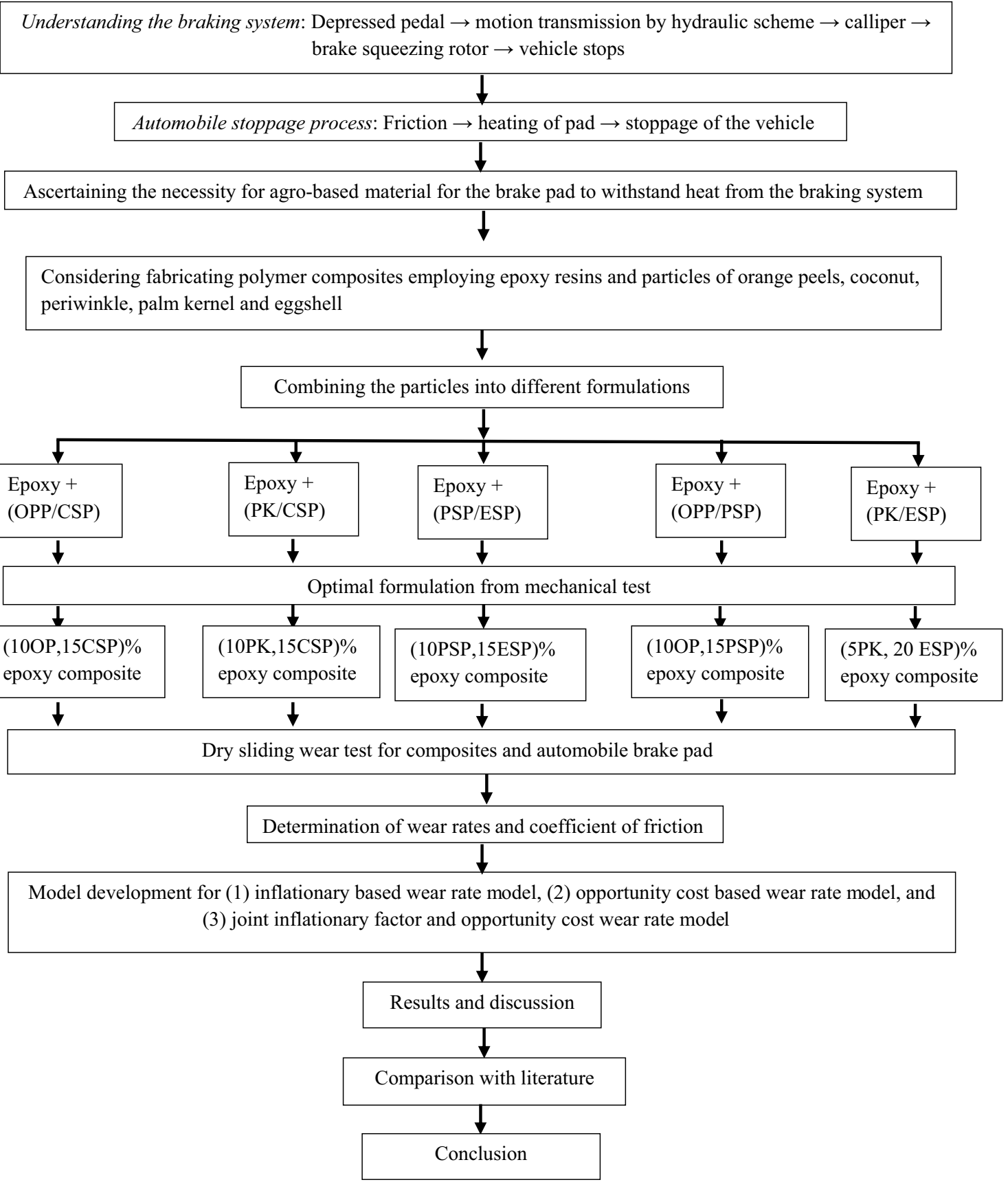

Fig. 1 a Research scheme for wear studies on epoxy composites and brake pad Cylindrical shaped specimens of varying diameters, notably four: $8,10,12$ and $15.5 \mathrm{~mm}$, were used for the experiments under three varied loads of 5, 7.5 and $15 \mathrm{~N}$ while each of the samples run for four different timings: 60, 120, 180 and 240 secs. b Rep- resentative SEM/EDS micrograph of (10OPp/15CSp)\% composite. c Representative SEM/EDS micrograph of (10PKSp/15CSp)\% composite. d Representative SEM/EDS micrograph of (10PSp/15ESp)\% composite. e Representative SEM/EDS micrograph of commercial grade brake pad 

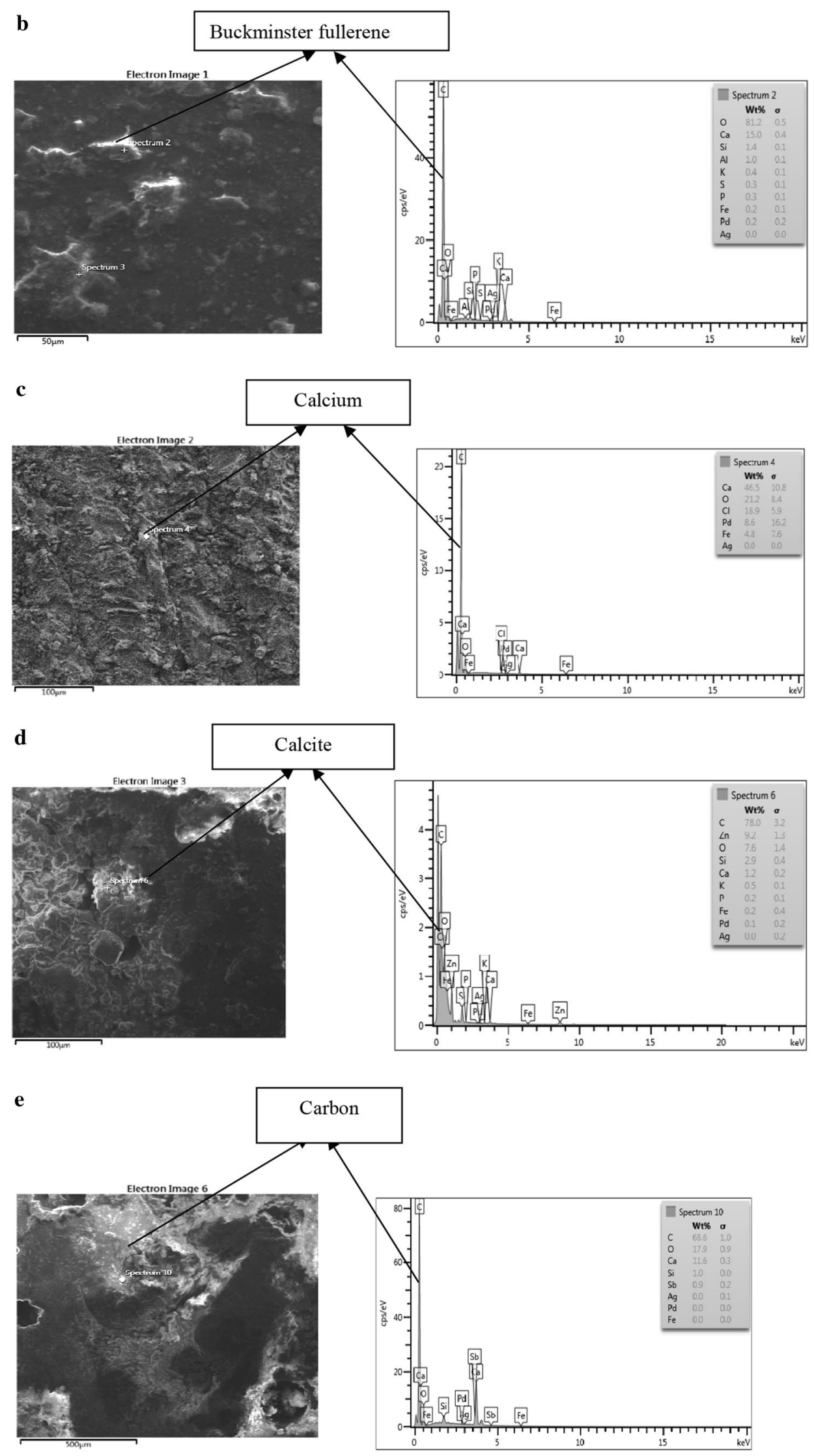

Fig. 1 (continued)

SN Applied Sciences

A SPRINGER NATURE journal 
Table 1 Formulations and descriptions

\begin{tabular}{lll}
\hline Formulation & Acronym & Description \\
\hline 1 & $10 \%$ OP $+15 \%$ CSP & $10 \%$ particulate orange peels $+15 \%$ particulate coconut shell + epoxy resin \\
2 & $10 \%$ PKSP $+15 \%$ CSP & $10 \%$ particulate palm kernel shells $+15 \%$ particulate coconut shell + epoxy resin \\
3 & $10 \%$ PSP $+15 \%$ ESP & $10 \%$ particulate periwinkle shells $+15 \%$ particulate eggshells + epoxy resin \\
4 & $10 \%$ OP $+5 \%$ PSP & $10 \%$ particulate orange peels $+5 \%$ particulate eggshells + epoxy resin \\
5 & $5 \% \mathrm{PK}+10 \%$ ESP & $5 \%$ particulate palm kernel shells $+10 \%$ particulate eggshells + epoxy resin \\
\hline
\end{tabular}

Table 2 Parametric ranges of the specimens for experiments

\begin{tabular}{lcclll}
\hline $\begin{array}{l}\text { Formula- } \\
\text { tions }\end{array}$ & Mass $(\mathrm{g})$ & $\begin{array}{l}\text { Height } \\
(\mathrm{cm})\end{array}$ & $\begin{array}{l}\text { Radius } \\
(\mathrm{cm})\end{array}$ & $\begin{array}{l}\text { Volume } \\
\left(\mathrm{cm}^{3}\right)\end{array}$ & $\begin{array}{l}\text { Density } \\
\left(\mathrm{g} / \mathrm{cm}^{3}\right)\end{array}$ \\
\hline $1-5$ & $\begin{array}{r}3.11- \\
4.16\end{array}$ & $\begin{array}{r}1.09- \\
1.45\end{array}$ & 0.775 & $2.71-2.75$ & $1.14-1.16$ \\
& & & & & \\
\hline
\end{tabular}

The specific wear rate $=$ wear volume

/(Normal load/sliding distance)

The sliding speed is the velocity and the coefficient of friction was determined by multiplying the weight of the specimen before each test by the velocity to give the momentum ( $\mathrm{N}$ ). As per Newton's law, where actions and reactions are equivalent and opposed, the frictional force is obtained by subtracting the momentum from the originally applied force.

Therefore,

COF $=$ Applied force/Frictional force

The wear rate was determined using the following, known as the Archard's model:

$W_{r}=\frac{V_{L}}{F_{N} S_{D}}$

where $V_{L}$ is the volume loss of the specimen in $\mathrm{mm}^{3}, F_{N}$ is the applied force in Newton, $\mathrm{N}$, and $S_{D}$ is the sliding distance in meters, $\mathrm{m}$

\subsection{Economics based wear rate models}

\subsubsection{The basis for the selection of Archard model}

Many studies on wear behaviour of composites with applications in engineering practices reveal that wear rate increase in composites is a central concern [1-5]. Moreover, a couple of studies in the manufacturing domain emphasize cost as a dominant factor in the progress assessment and determining the sustainability of the system. For instance, Shehab et al. [52] declared that the application of composites increased considerably in aerospace structures but further usage was threatened by the high material and manufacturing costs. Consequently, they asserted that it is necessary to develop cost estimation instruments to accurately estimate the cost at the initial design phases, and then cost-effective decisions and design optimisation can be accomplished to lower the cost of composite products. But while the research theme promotes cost estimation, there is a prominent research theme that advocates for wear rate analysis. Unfortunately, there has not been any meeting point for these ideas in the composite literature yet though synergy of ideas is flourishing in scientific investigations. There is, therefore, the necessity to integrate these ideas the development of a pseudo wear rate model that capture both the inflationary cost and the wear rate technical parameters.

Besides, a typical wear appraisal problem is to tackle the wear rate concept using a technically sound and economically inclined idea. Thus, a trade-off is required among the technical and economic (inflationary cost) needs to wear rate appraisal to resolve the serious task of finding a feasible strategy for the synergic modelling effort. Furthermore, it is compelling for researchers to consider the possible model development using a method that could assist in practice and still retain a good theoretical framework. This model could assist in practice and still retain a good theoretical framework. This model would help to have an understanding of the elements of the model and the interactions among them, which will entail the important real-life feature for wear rate modelling. However, due to the decision variables and their associations, the complication involved in such modelling emerges and should be resolved. Therefore, the Archard model of wear appraisal would be the best fit analytical tool to aid the wear rate decisions for the wear rate appraisal problem of concern in this work. The Archard model is straightforward with no computational complexity for practical usage in the industry. So, the Archard model is a method useful for wear rate problem in brake pad applications in automobiles. Archard method is deployed in this work with the introduction of inflationary cost into the model. 


\subsubsection{Inflationary factor-based wear rate model}

The monthly inflationary factor was applied to the wear parameters of the composites as a means of predicting the wear rates of the composites using the parameters as the working conditions in a month. The incorporation of the monthly inflationary factor into the wear rate model correctly reveals the wear performance of the considered samples in a practical economically-influenced environment in which the products are to be used in reality. Therefore, we have

$W_{r . \text { inf }}=\left(\frac{V_{L}}{F_{N} S_{D}} \cdot\left(1+\frac{\theta}{12}\right)^{n}\right)$

where $\theta$ is the inflationary factor, obtained from the National Bureau of Statistics as $17.24 n$ is the period of analysis taken as 1 year, while 12 represents the number of months in a year.

During the service life of organic-based composites, materials are removed from their surfaces, damaging their strengths and compromising the integrity of the composites. The rate of material removal is an important element to establish the possible lifespan of the composite, maintenance and replacement costs. However, a general rise in cost with associated enhancement in the quality of the composites exists, which impacts on cost decisions of the composite engineer. This, cost, referred to as inflation, is important and very frequently associates with decisions to replace the composites and maintenance cost over time. It may have a multiplier effect as the cost of composite inputs such as resins, moulds, spaced for fabrication and labour cost for composite manufacturing may trigger a rise in the cost of producing composites. Consequently, inflation becomes a substantial parameter when deciding on modelling the wear rate for the organic-based composites.

\subsubsection{Opportunity cost-based wear rate model}

The opportunity cost was applied in this investigation as the alternative cost of carrying out all production and analysis leading to the wear rate of each sample. In this work, the cost of materials, transportation and wear experiment was estimated per sample. These costs represent the benefit, profit or values that were forgone to determine the wear rate of each sample. Each of the five formulations considered in this investigation has four samples making a total of twenty samples. Therefore, the opportunity cost for each of the twenty samples will be estimated by dividing the total estimated cost by the total number of samples as follows: $k t=1 / n($ cost of materials + cost of transportation

+ cost of wear experiment)

where $k$ is the opportunity cost relating to the determination of the wear rate of each sample, $t$ is the time frame considered and $n$ is the total number of samples involved in the process.

During the fabrication of organic-based composites, a choice must be made on which filler to use or the matrix to select in the fabrication process. As these options are selected, an opportunity cost exists, which is the cost of not benefiting from others while enjoying the best option. But opportunity cost is often associated with cost decisions while fabricating composites. This parameter is very necessary to be incorporated into the analysis of wear rate for organic-based composites during composite development.

The opportunity cost based wear rate model is introduced into the wear rate model, described mathematically as follows:

$W_{r+k t}=\left(\left(\frac{V_{L}}{F_{N} S_{D}}\right)+k t\right)$

\subsubsection{Joint inflationary factor and opportunity cost model based wear rate model}

The inflationary factor and opportunity cost indices were further incorporated into the wear rate model to factor in the cost of inflation and alternative forgone in the wear rate of each sample. Thus, we have:

$W_{r . \text { inf }+k t}=\left(\frac{V_{L}}{F_{N} S_{D}}\left(1+\frac{\theta}{12}+k t\right)^{n}\right)$

For Eqs. (4), (6) and (7), the wear rate will be measured in $\mathrm{mm}^{3} / \mathrm{Nm}$, because other quantities in the model are dimensionless and are subject to peculiar changes in the region or country where they are being applied.

In composite development, inflation factor and opportunity cost impacts on the cost-effectiveness of the development endeavour. Nonetheless, it is essential to include these parameters when contemplating on developing organic-based composites.

\section{Results and discussion}

The five different composites: (100Pp, 15CSp), (10PKSp,15CSp), (10PSp, 15ESp), (10OPp,15PSp) and (5PKSp,20ESp)\% which exhibited the best mechanical properties from each composite group, were selected for the wear test alongside the commercial grade brake pad (Table 3). The result of the wear test was obtained in terms of wear rate from 2 scenarios. The first scenario was by 
Table 3 Wear rate results for the developed composites and commercial grade brake pad

\begin{tabular}{|c|c|c|c|c|c|c|}
\hline $\begin{array}{l}\text { Applied } \\
\text { load (N) }\end{array}$ & $\begin{array}{l}\text { (OPp/CSp) } \\
\left(\mathrm{mm}^{3} / \mathrm{N} . \mathrm{m}\right)\end{array}$ & $\begin{array}{l}(\mathrm{PKSp} / \mathrm{CSp}) \\
\left(\mathrm{mm}^{3} / \mathrm{N} \cdot \mathrm{m}\right)\end{array}$ & $\begin{array}{l}\text { (PSp/ESp) } \\
\left(\mathrm{mm}^{3} / \mathrm{N} . \mathrm{m}\right)\end{array}$ & $\begin{array}{l}\text { (OPp/PSp) } \\
\left(\mathrm{mm}^{3} / \mathrm{N} . \mathrm{m}\right)\end{array}$ & $\begin{array}{l}\text { (PKSp/ESp) } \\
\left(\mathrm{mm}^{3} / \mathrm{N} \cdot \mathrm{m}\right)\end{array}$ & $\begin{array}{l}\text { Commer- } \\
\text { cial grade } \\
\left(\mathrm{mm}^{3} / \mathrm{N} . \mathrm{m}\right)\end{array}$ \\
\hline \multicolumn{7}{|c|}{ Scenario 1} \\
\hline \multicolumn{7}{|c|}{ Agarwal et al. [54] wear rate model } \\
\hline 5 & 3 & 1.5 & 0.64 & 3.01 & 2.76 & 3.64 \\
\hline 7.5 & 1.1 & 0.77 & 0.38 & 2.06 & 2.84 & 1.96 \\
\hline 10 & 1.11 & 0.72 & 0.3 & 0.8 & 2.23 & 1.06 \\
\hline 15 & 0.75 & 0.9 & 0.19 & 0.43 & 1.99 & 0.65 \\
\hline \multicolumn{7}{|c|}{ Scenario 2} \\
\hline \multicolumn{7}{|c|}{ Newly developed wear rate model } \\
\hline 5 & 5.23 & 3.65 & 1.55 & 7.34 & 6.74 & 8.88 \\
\hline 7.5 & 2.69 & 1.88 & 0.93 & 5.03 & 6.93 & 4.78 \\
\hline 10 & 2.71 & 1.76 & 0.72 & 1.95 & 5.44 & 2.61 \\
\hline 15 & 1.82 & 2.2 & 0.46 & 1.04 & 4.84 & 1.58 \\
\hline
\end{tabular}

Agarwal et al. [54] which is the Archard wear model and the second scenario is the developed wear rate model from this work (Table 3).

\subsection{Scanning electron microscopy (SEM)/ energy dispersive spectroscopy (EDS) tests on the samples}

The scanning electron microscopy (SEM) is a characterisation technique that is used to produce images from a material after its surface has been examined with the concentration of a beam of electrons. The samples were carbon coated and held steadily in a sample holder with a double sized carbon tape before they were placed in a sample chamber. The acceleration voltage used in the imaging of the samples was $20 \mathrm{kV}$. The energy dispersive spectroscopy (EDS) is carried out alongside the SEM for elemental composition of the microstructure of a given sample. The representative SEM/EDS micrographs in Figs. $1(b-e)$ have been used to identify the dominant phase in the microstructure of each of the composite blends as well as that of the commercial grade brake pad.

1. Orange peel/coconut shell blend: (10OPp/15CSp)\% epoxy composite

2. Palm kernel/coconut shell blend: (10PKSp/15CSp)\% epoxy composite

3. Periwinkle/egg shell blend: (10PSp/15ESp)\% epoxy composite

4. Commercial grade brake pad

In this paper, only figures explaining the $8 \mathrm{~mm}$ and $15 \mathrm{~mm}$ samples are shown for coinciseness. However, discussion of results is extended to all categories of samples i.e. the $8,10,12$ and $15.5 \mathrm{~mm}$ samples.

\subsection{Effect of AL (applied load) and SD (sliding distance) on the SWR (specific wear rate) of $(100 \mathrm{P}, 15 \mathrm{CSP}) \%$ epoxy composite}

For the $8 \mathrm{~mm}$ sample, the specific wear rate decreased with increasing sliding distance and increased with higher applied loads. However, it was highest with the $7.5 \mathrm{~N}$ load. In the $10 \mathrm{~mm}$ specimen, the wear rate decreased under higher sliding distance and reduced with higher loads except under $5 \mathrm{~N}$ where it increased with greater sliding distance. The $12 \mathrm{~mm}$ specimen experienced higher wear rate as the sliding distance increased but the wear rate declined with increase in applied loads. The $15 \mathrm{~mm}$ sample recorded the highest wear rates with increasing sliding distance as the applied load reduced with the highest wear rate obtained under the application of $5 \mathrm{~N}$.

\subsection{Effect of AL and SD on the SWR of (10PK, 15 CSP)\% epoxy composite}

The wear rate of the $8 \mathrm{~mm}$ specimen decreased with higher sliding distance but increased from 56.52 to $75.36 \mathrm{~m}$ under 5 and 7.5 applied loads. For the $10 \mathrm{~mm}$ and $12 \mathrm{~mm}$ specimens, higher wear rates with increasing sliding distance and reduced loads were noticed due to the increase in surface area of the sample used. The wear rates of the $15.5 \mathrm{~mm}$ specimen were the highest due to a larger cross-sectional area but it reduced with increasing sliding distance and reduced significantly with higher loads. 


\subsection{Effect of AL and SD on the SWR of (10PSP, $15 E S P) \%$ epoxy composite}

The highest wear rate experienced by the $8 \mathrm{~mm}$ sample was under an applied load of $7.5 \mathrm{~N}$ but the wear rate dropped with the increase in sliding distance. The wear behaviour of the $10 \mathrm{~mm}$ sample shows significantly reduced values with higher load application but reduced with a higher sliding distance. The $12 \mathrm{~mm}$ sample showed a similar behaviour to that of the $10 \mathrm{~mm}$ sample. For the $15 \mathrm{~mm}$ sample, wear rates declined as the sliding distance increased.

\subsection{Effect of AL and SD on the SWR of (10OP,15PSP)\% epoxy composite}

For the $8 \mathrm{~mm}$ sample, wear rates reduced with increasing sliding distance and reduced with higher sliding distance. For the $12 \mathrm{~mm}$ sample, the increase in the surface area resulted in higher wear rate. With the $5 \mathrm{~N}$ load, the wear rate began at $2.66 \mathrm{~mm}^{3} / \mathrm{Nm}$ before dropping to $1.03 \mathrm{~mm}^{3}$ / $\mathrm{Nm}$. The wear rate of the $12 \mathrm{~mm}$ sample under $7.5 \mathrm{~N}$ began at $2.2 \mathrm{~mm}^{3} / \mathrm{Nm}$ and reduced continuously with increasing sliding distance to $0.73 \mathrm{~mm}^{3} / \mathrm{Nm}$. Further increase of load to $15 \mathrm{~N}$ resulted in a lower wear rate of $1.25 \mathrm{~mm}^{3} / \mathrm{Nm}$ which dropped to $0.4 \mathrm{~mm}^{3} / \mathrm{Nm}$ after the sliding distance reached $75.36 \mathrm{~m}$. For the $15.5 \mathrm{~mm}$ sample, higher wear rates existed under loads. The $15.5 \mathrm{~mm}$ sample exhibited the highest wear rates under $5 \mathrm{~N}$ load with a magnitude of $3.02 \mathrm{~mm}^{3} / \mathrm{Nm}$. The sample experienced lower wear rates under higher wear loads. For all loads, the wear rates reduced with increasing sliding distance.

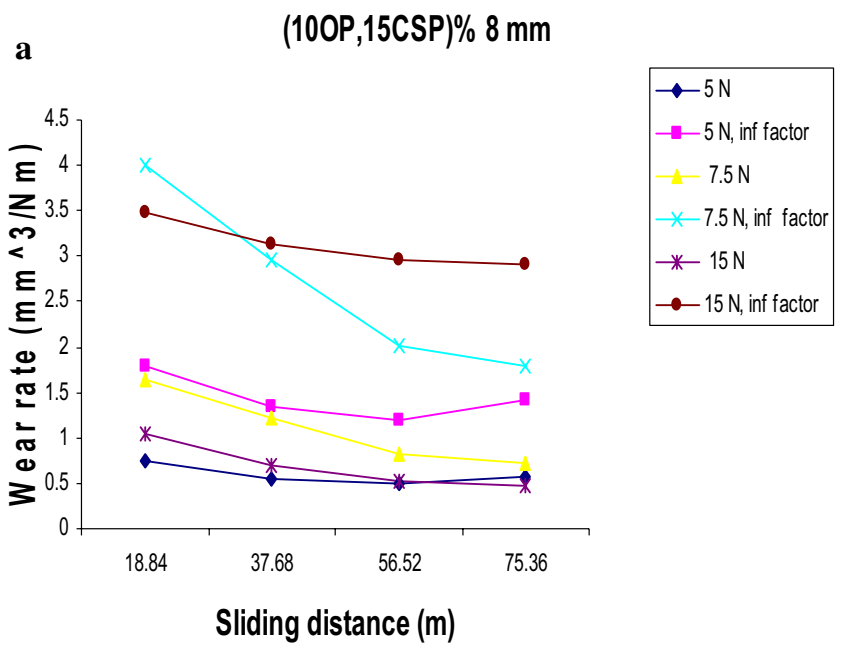

Fig. 2 Effect of an inflationary factor on the specific wear rate of (10OP, 15 CSP)\% epoxy composite. a Effect of an inflationary factor on the wear rates of $8 \mathrm{~mm}(100 \mathrm{P}, 15 \mathrm{CSP}) \%$ epoxy compos-

\subsection{Effect of AL and SD on the SWR of (5 PK,20PSP)\% epoxy composite}

The $8 \mathrm{~mm}$ sample, exhibited the highest wear rates under $5 \mathrm{~N}$ load while lower wear rates were displayed under the application of the $15 \mathrm{~N}$ load. The wear rates reduced with increasing sliding distance, similar to 10 and $12 \mathrm{~mm}$ samples. The wear rates also declined with an increased load and higher sliding distance. The $15.5 \mathrm{~mm}$ sample exhibited wear rates higher than other samples. However, the highest wear rates was for $7.5 \mathrm{~N}$ then $5 \mathrm{~N}$. For $15 \mathrm{~N}$, the wear rate increased to $2.9 \mathrm{~mm}^{3} / \mathrm{Nm}$ after a sliding distance of $37.68 \mathrm{~m}$ (highest). The wear rate declined for all loads with an increased sliding distance.

\subsection{Effect of AL and SD on the SWR of automobile brake pad}

For the brake pad, only the $15.5 \mathrm{~mm}$ specimen was considered. Under the application of $5 \mathrm{~N}$ load, the brake pad sample exhibited a wear rate of $2.58 \mathrm{~mm}^{3} / \mathrm{Nm}$ which reduced gradually to $1.57 \mathrm{~mm}^{3} / \mathrm{Nm}$ while under the $15 \mathrm{~N}$ load its wear rate reduced gradually from 1.63 to $1.19 \mathrm{~mm}^{3} / \mathrm{Nm}$ with increasing sliding distance. However, under the $7.5 \mathrm{~N} \mathrm{load}$, the wear rate of the specimen increased from $1.53 \mathrm{~mm}^{3} / \mathrm{Nm}$ to a peak value of $3.05 \mathrm{~mm}^{3} / \mathrm{Nm}$.

\subsection{Effect of IF (inflationary factor) on the SWR of epoxy composites}

The wear rate increased significantly as shown by Fig. 2 by an average of $225.36,143.2,143.9$ and $143.46 \%$, for the $8,10,12$ and $15.5 \mathrm{~mm}$ samples respectively. The highest

b $\quad(100 \mathrm{P}, 15 \mathrm{CSP}) 15.5 \mathrm{~mm}$
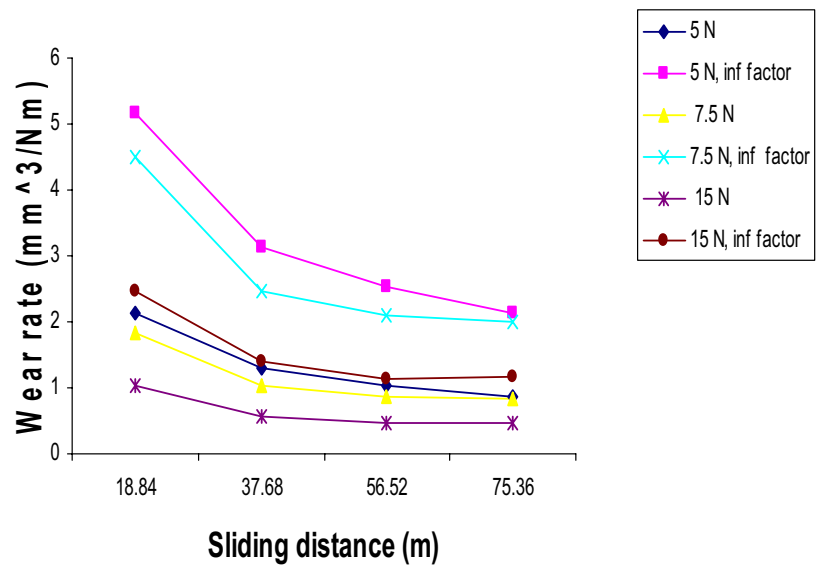

ite. $\mathbf{b}$ Effect of an inflationary factor on the wear rates of $15.5 \mathrm{~mm}$ (10OP,15 CSP)\% epoxy composite 
percentage increase in wear rate was obtained as 5.18 $\mathrm{mm}^{3} / \mathrm{Nm}$ by the $15.5 \mathrm{~mm}$ sample under an applied load of $5 \mathrm{~N}$ at a sliding distance of $18.8 \mathrm{~mm}$.

After the introduction of the wear rate inflationary factor model to the (10PK,15CSP)\% epoxy composite, the percentage increase in wear rate of the $8,10,12$ and $15.5 \mathrm{~mm}$ samples were $143.76,141.99,143.43$ and $142.94 \%$ respectively. Figure 3 describes the increase in the wear rates of the composite with the highest wear rate of $5.22 \mathrm{~mm}^{3}$ / $\mathrm{Nm}$ was obtained by the $15.5 \mathrm{~mm}$ sample by the under the application of $5 \mathrm{~N}$.

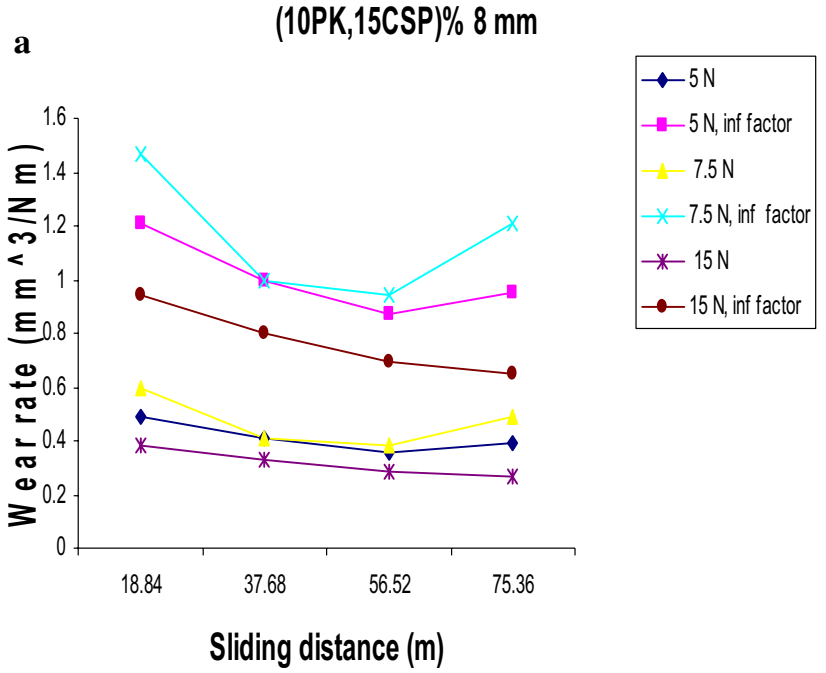

Fig. 3 Effect of an inflationary factor on the specific wear rate of (10 $\mathrm{PK}, 15 \mathrm{CSP}) \%$ epoxy composite. a Effect of an inflationary factor on the wear rate of $8 \mathrm{~mm}(10 \mathrm{PK}, 15 \mathrm{CSP}) \%$ epoxy composite. $\mathbf{b}$ Effect of
For the (10PSP,15ESP)\% composite, the wear rate increased by $140.45,144.66,142.07$ and $142.85 \%$ for the $8,10,12$ and $15.5 \mathrm{~mm}$ samples, respectively, with the introduction of the inflationary factor into the wear rate equation described by Eq. (4). The effect of the new wear rate model on the composites is shown in Fig. 4, with the highest wear rate recorded by the $3.79 \mathrm{~mm}^{3} / \mathrm{Nm}$ by the $15.5 \mathrm{~mm}$ sample with a load of $5 \mathrm{~N}$.

The wear rate inflationary factor model increased the wear rate of the (100P, 15PSP)\% epoxy composite by $142.8,110.84,298.34$ and $143.69 \%$ for the $8,10,12$ and $15.5 \mathrm{~mm}$ samples, respectively. Figure 5 shows the

b $\quad(10 \mathrm{PK}, 15 \mathrm{CSP}) \% 15.5 \mathrm{~mm}$

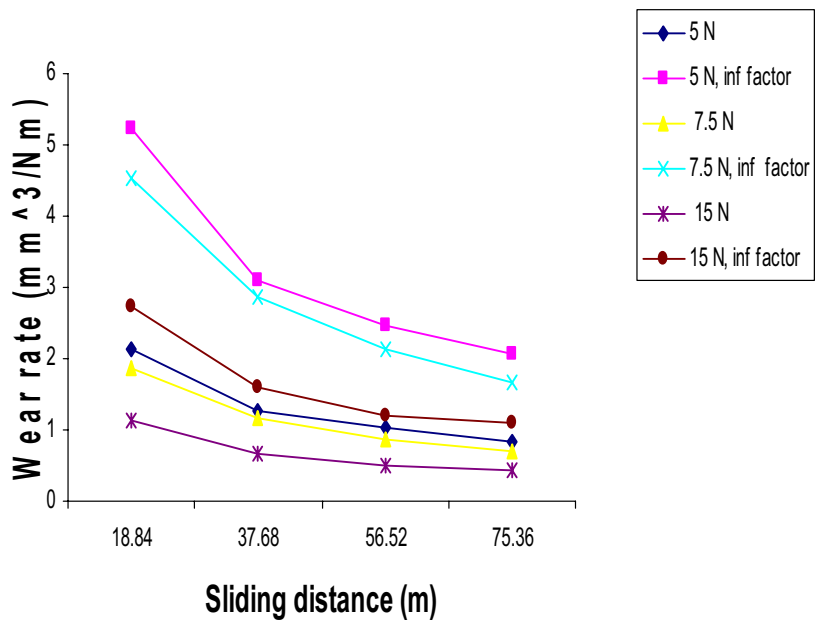

an inflationary factor on the wear rate of $15.5 \mathrm{~mm}(10 \mathrm{PK}, 15 \mathrm{CSP}) \%$ epoxy composite

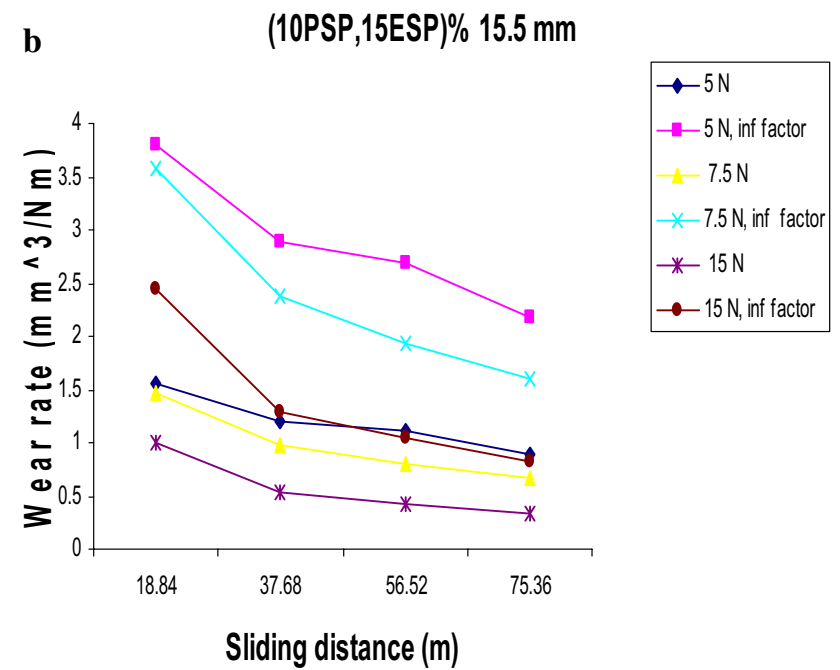

Fig. 4 Effect of an inflationary factor on the specific wear rate of (10 PSP, 15ESP)\% epoxy composite. a Effect of IF on the WR of 8 mm (10PSP, 15ESP)\% epoxy composite. b Effect of IF on the WR of $15.5 \mathrm{~mm}$ (10PSP, 15ESP)\% epoxy composite 
a

(100P,15PSP)\% $8 \mathrm{~mm}$

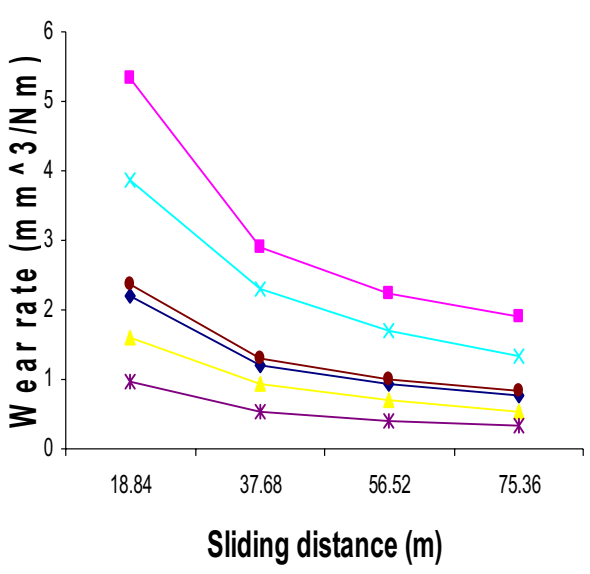

Fig. 5 Effect of an inflationary factor on the specific wear rate of (10OP, 15PSP)\% epoxy composite. a Effect of an inflationary factor on the wear rates of $8 \mathrm{~mm}(10 \mathrm{OP}, 15 \mathrm{PSP}) \%$ epoxy compos-

influence of the model on the wear rates of the composites, with the $15.5 \mathrm{~mm}$ sample exhibiting the highest wear rate of $7.36 \mathrm{~mm}^{3} / \mathrm{Nm}$ with a load application of $5 \mathrm{~N}$ at a distance of $18.36 \mathrm{~m}$.

The introduction of the inflationary factor into the wear rate model increased the wear rates of the $5 \mathrm{PK}$, 20ESP)\% composite as described by Fig. 6 . This represents an increase of $144.72,143.55,235.39$ and $143.46 \%$ in the average wear rate of the $8,10,12$ and $15.5 \mathrm{~mm}$ samples after introducing the monthly inflationary factor to the wear rate model. The highest wear rate of 11.18

$\mathbf{a}$

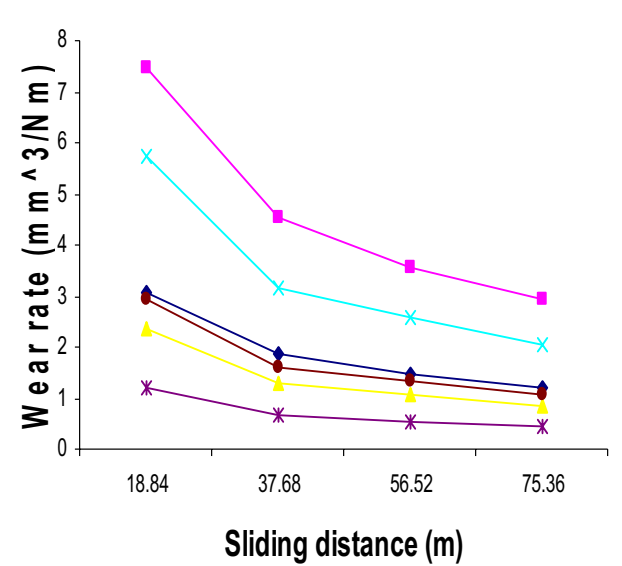

Fig. 6 Effect of an inflationary factor on the specific wear rate of (10OP, 15PSP)\% epoxy composite. a Effect of an inflationary factor on the wear rates of $8 \mathrm{~mm}(5 \mathrm{PK}, 20 \mathrm{ESP}) \%$ epoxy composite. $\mathbf{b}$ Effect b

(100P,15PSP)\% $15.5 \mathrm{~mm}$

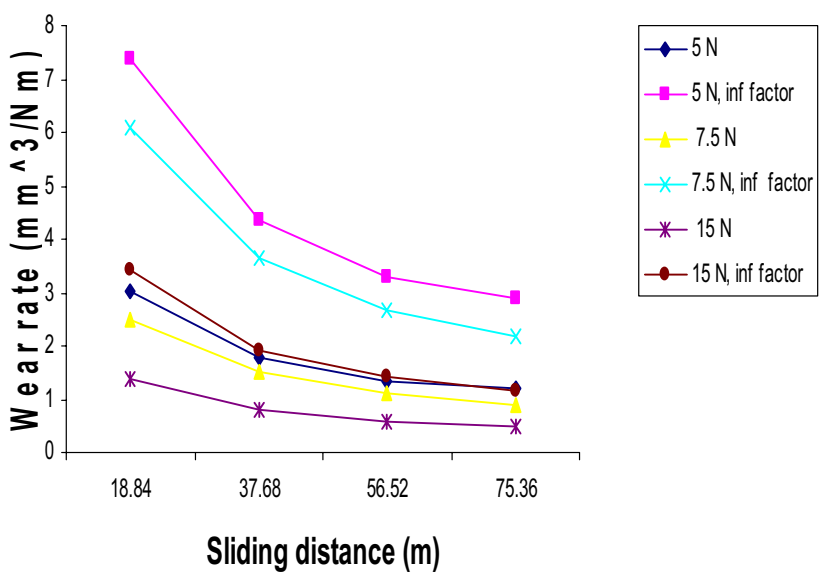

ite. b Effect of an inflationary factor on the wear rates of $15.5 \mathrm{~mm}$ (100P, 15PSP)\% epoxy composite

$\mathrm{mm}^{3} / \mathrm{Nm}$ obtained in this category is by the $15.5 \mathrm{~mm}$ sample under a load of $7.5 \mathrm{~N}$.

Lastly, the brake pad sample exhibited an increase in wear rate of $143.44 \%$ with the introduction of the inflationary factor into the wear rate model (Fig. 7). This highest wear rate was obtained by the brake pad sample was 7.44 $\mathrm{mm}^{3} / \mathrm{Nm}$ with an applied force of $7.5 \mathrm{~N}$.

\subsection{Opportunity cost}

$k t=1 / 20(\mathrm{~N} 15,000+\mathrm{N} \mathrm{5,000}+\mathrm{N} 48,000)=\mathrm{N} \mathrm{3,400}$ or $0.034 /$ $\mathrm{N} 1,000$.

$\mathbf{b}$

(5PK,20ESP)\% $15.5 \mathrm{~mm}$
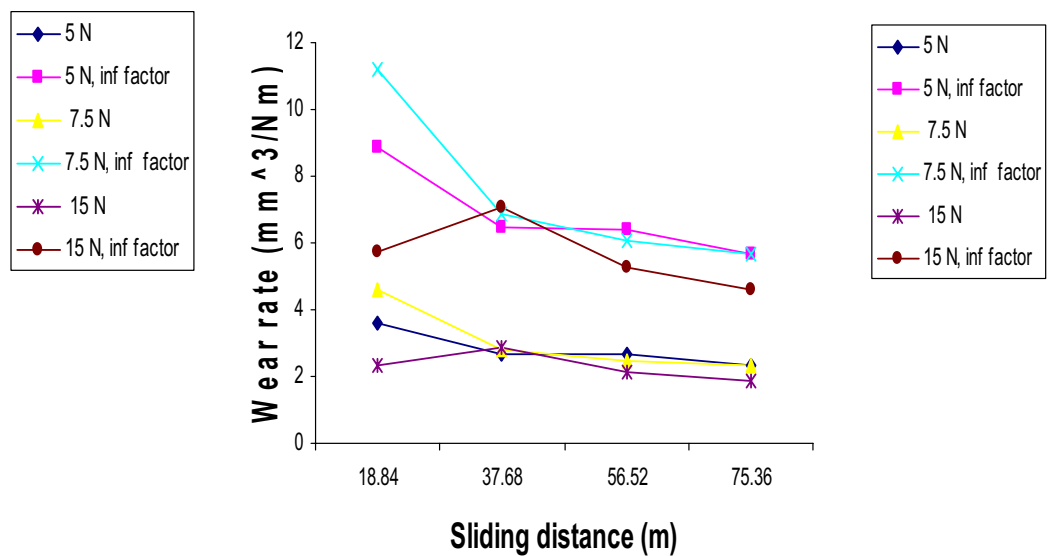

of an inflationary factor on the wear rates of $15.5 \mathrm{~mm}$ (5PK,20ESP)\% epoxy composite 
(Brake pad) $15.5 \mathrm{~mm}$

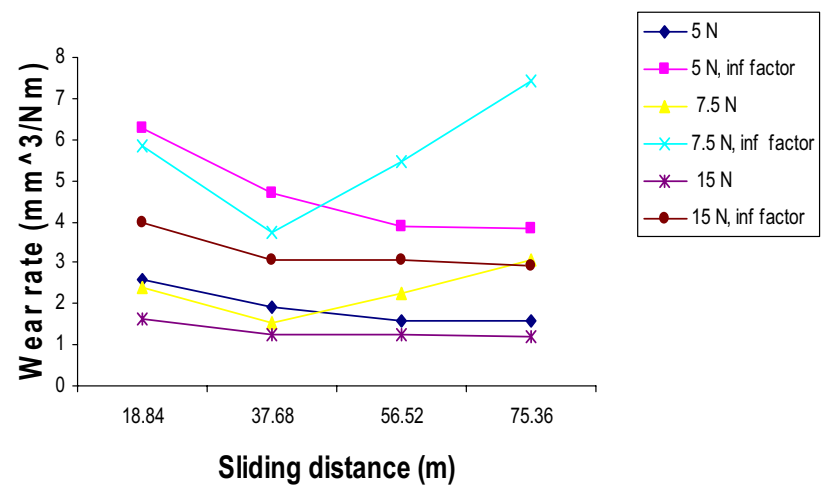

Fig. 7 Effect of applied loads and sliding distance on the wear rates of brake pad sample

\subsection{Effect of OC (opportunity cost) on WR of epoxy composites}

The addition of the opportunity cost factor into the wear rate model resulted in a percentage increase in the wear rate of the (100P, 15CSP)\% composite by an average of $4.59 \%$. Figure 8 shows the influence of the opportunity cost factor on the wear rate. The $8 \mathrm{~mm}$ sample exhibited the highest percentage increase in wear rate with $5.03 \%$, followed by the 12,10 and $15 \mathrm{~mm}$ samples with increase in wear rate of $4.79,4.64$ and $3.9 \%$, respectively.

The effect of the opportunity cost factor on the wear rate model is described by Fig. 9 . the (10PK, 15CSP)\% composite exhibited a higher percentage increase in wear rate due to the inclusion of the opportunity cost in the wear rate model. The percentage increases in wear rate were recorded as $9.71,7,4.98$ and $3.97 \%$ for the $8,10,12$ and $15.5 \mathrm{~mm}$ samples, respectively.

The influence of the opportunity cost on the wear rate of the (10PSP, 15ESP)\% composite is described in Fig. 10. The (10PSP, 15ESP)\% composite experienced a percentage increase in wear rate by $5.24 \%$. The $10 \mathrm{~mm}$ sample experienced the highest increase of $5.82 \%$, while the 8,12 and $15.5 \%$ samples exhibited $5.62,5.04$ and $4.48 \%$ increase, respectively.

For the (100P, 15PSP)\% composite, the wear rate increased by $3.87 \%$ due to the influence of the opportunity cost in the wear rate model (Fig. 11). The percentage increase reduced gradually as the sample diameter increases with $4.54,3.98,3.65$ and $3.32 \%$ for the $8,10,12$ and $15.5 \mathrm{~mm}$ samples, respectively.

The effect of the opportunity cost on the wear rate of the $(5 \mathrm{PK}, 20 \mathrm{ESP}) \%$ composite resulted in a percentage increase in wear rate of $2.56 \%$ (Fig. 12). This effect was obtained as $3.57,2.76,2.66$ and $1.25 \%$ for the $8,10,12$ and $15.5 \mathrm{~mm}$ samples, respectively.

The brake pad sample experienced a percentage increase of $1.91 \%$ in its wear rate due to the influence of the opportunity cost in the wear rate model (Fig. 13).

\subsubsection{Combined effects of IF and OC on the WR (wear rate) of composites}

The effect of the wear rate, inflationary factor and opportunity cost model as described by Eq. (7) on the (10OP, $15 \mathrm{CSP}) \%$ composite is shown by Fig. 14 . The composite recorded $149.08,148.44,148.54$ and $147.43 \%$ percentage increase in wear rate by the $8,10,12$ and $15.5 \mathrm{~mm}$ samples, respectively. The highest wear rate was recorded as 5.21
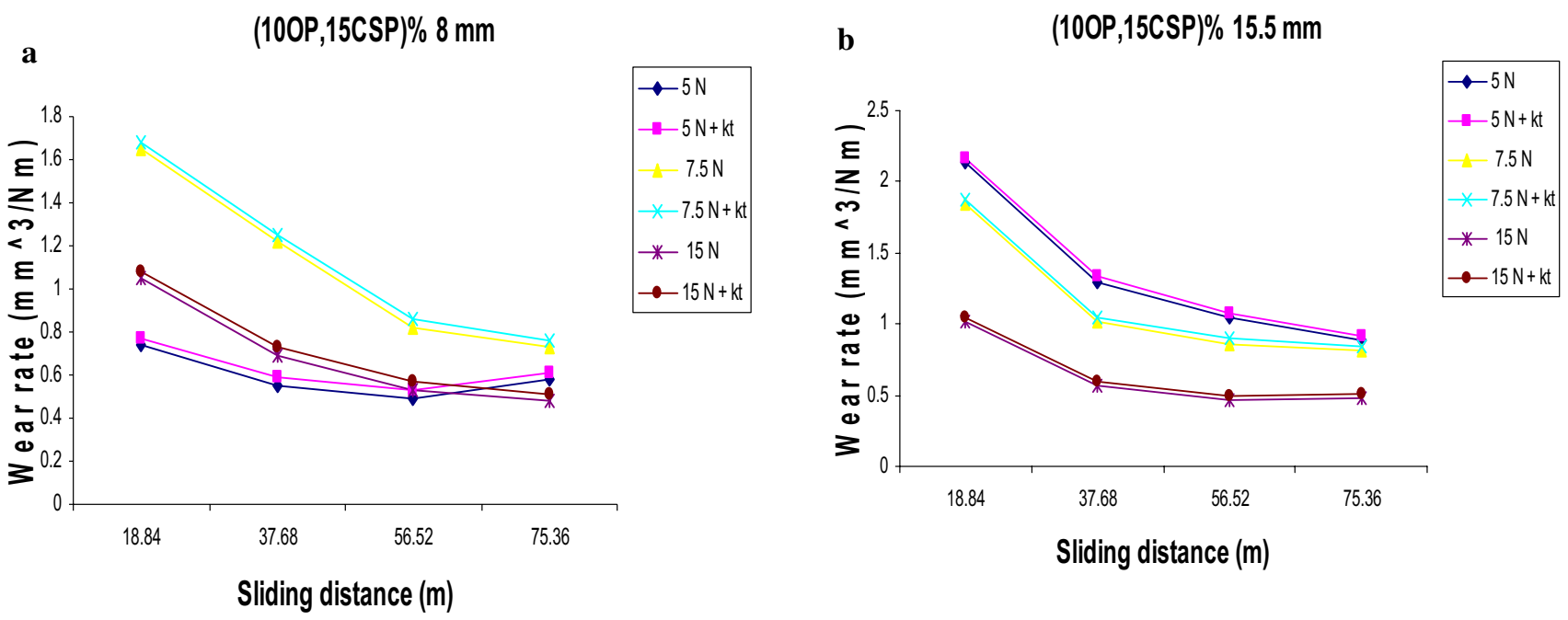

Fig. 8 Effect of opportunity cost on the specific wear rate of (10OP, 15CSP)\% epoxy composite. a Effect of OC on the WR of $8 \mathrm{~mm}$ (10OP, 15CSP)\% epoxy composite. b Effect of OC on the WR of $12 \mathrm{~mm}(100 \mathrm{P}, 15 \mathrm{CSP}) \%$ epoxy composite 
a

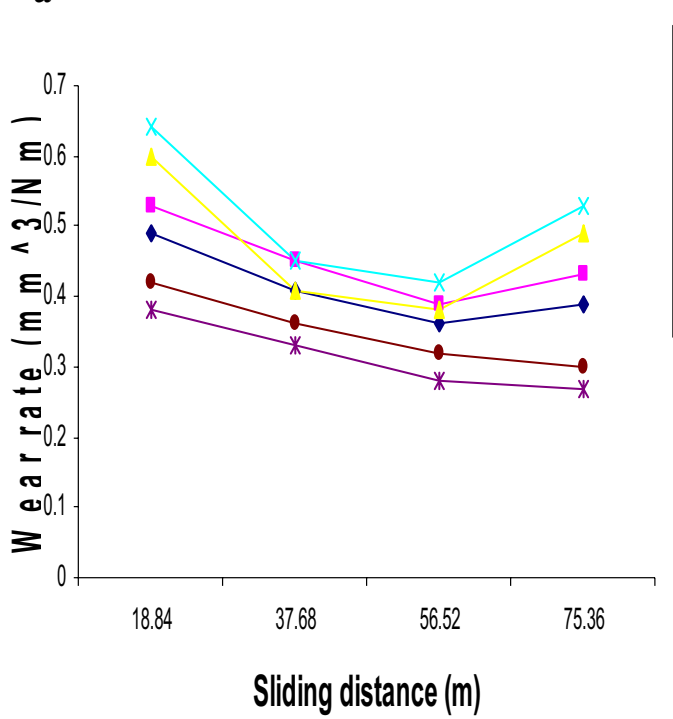

b

(10PK,15CSP) $15.5 \mathrm{~mm}$

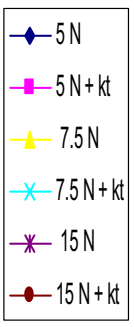

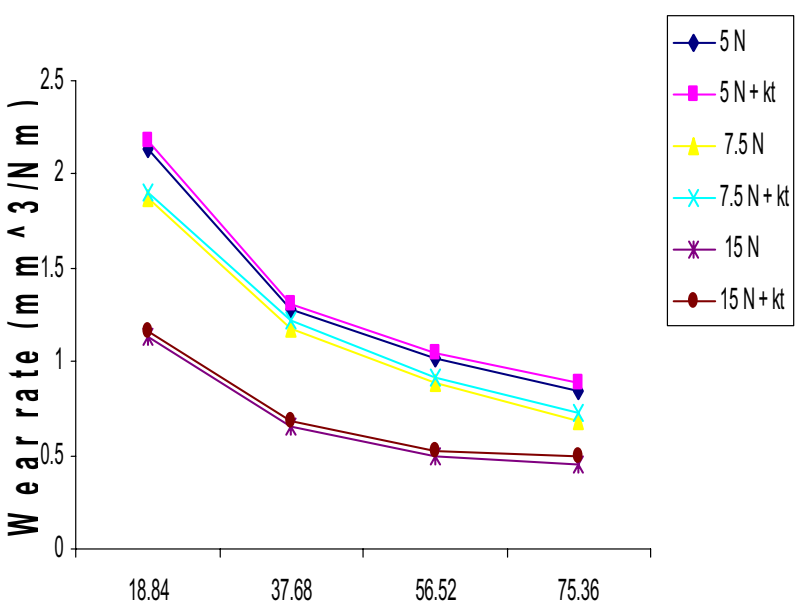

Fig. 9 Effect of opportunity cost on the specific wear rate of (10OP, 15CSP)\% epoxy composite. a Effect of opportunity cost on the wear rates of $8 \mathrm{~mm}(10 \mathrm{PK}, 15 \mathrm{CSP}) \%$ epoxy composite. $\mathbf{b}$ Effect of OC on the WR of $15.5 \mathrm{~mm}$ (10PK,15CSP)\% epoxy composite
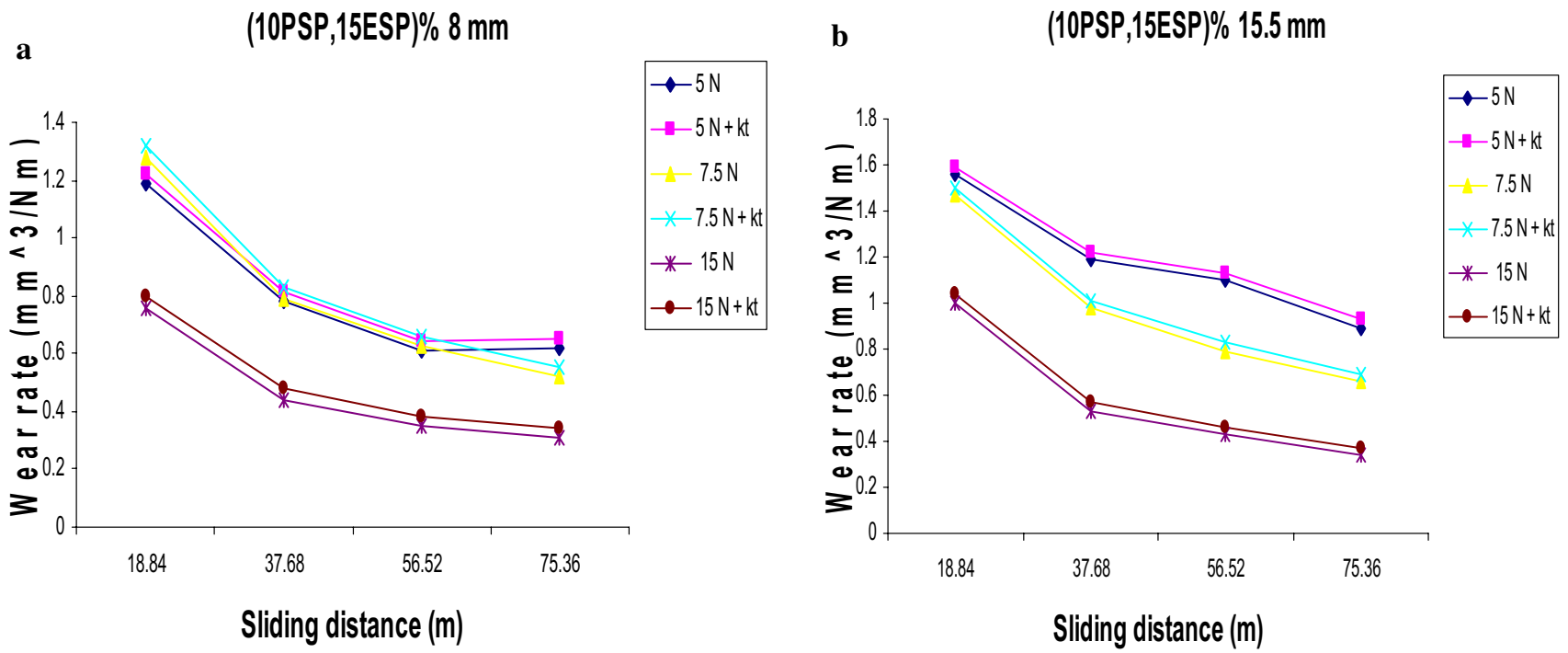

Fig. 10 Effect of opportunity cost on the specific wear rate of (10PSP, 15ESP)\% epoxy composite. a Effect of OC on the WR of 8 mm (10PSP,15ESP)\% epoxy composite. b Effect of OC on the WR of $15.5 \mathrm{~mm}$ (10PSP,15ESP)\% epoxy composite

$\mathrm{mm} 3 / \mathrm{Nm}$ by the $15.5 \mathrm{~mm}$ sample under a load of $5 \mathrm{~N}$ and $18.84 \mathrm{~m}$ sliding distance.

Figure 15 shows the influence of the wear rate, inflationary factor and opportunity cost model on the wear behaviour of the (10PK, 15CSP)\% composite. The composite experienced a $154.19,150.89,148.84$ and $147.7 \%$ percentage increase in wear rates for the $8,10,12$ and $15.5 \mathrm{~mm}$ samples. Despite the huge percentage increase, the highest wear rate recorded was $5.25 \mathrm{~mm}^{3} / \mathrm{Nm}$ by the $15.5 \mathrm{~mm}$ sample with an applied load of $5 \mathrm{~N}$ and $18.84 \mathrm{~m}$ sliding distance.

The application of the wear rate, inflationary factor and opportunity cost model on the (10PSP, 15ESP)\% composite wear behaviour is shown in Fig. 16. The composite exhibited a percentage increase of $149.22,150.02$, 148.64 and $148.05 \%$ by the $8,10,12$ and $15.5 \mathrm{~mm}$ samples, 


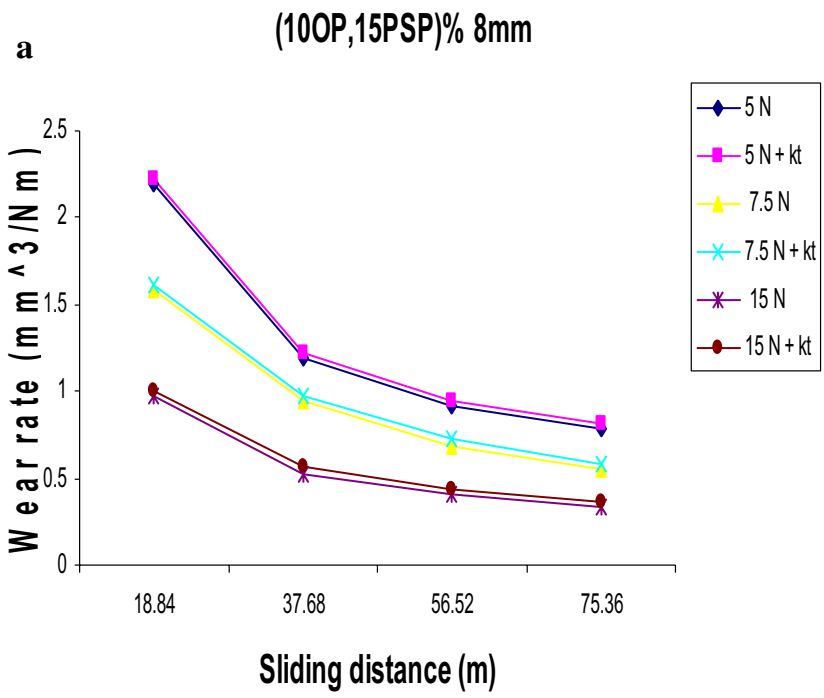

b $\quad(100 \mathrm{P}, 15 \mathrm{PSP}) \% 15.5 \mathrm{~mm}$

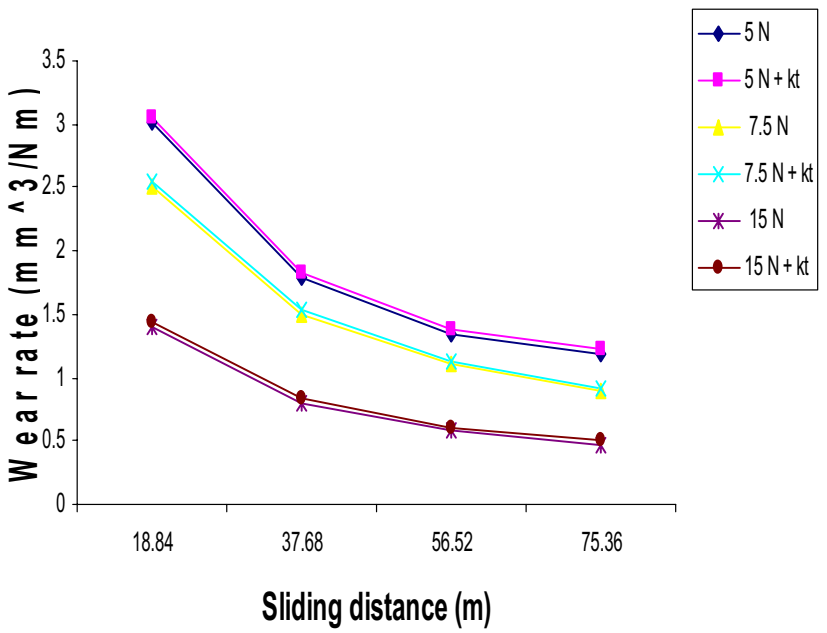

Fig. 11 Effect of OC on the SWR of (10PSP,15ESP)\% epoxy composite. a Effect of OC on the WR of $8 \mathrm{~mm}$ (10OP,15PSP)\% epoxy composite. b Effect of OC on the WRof $15.5 \mathrm{~mm}$ (10PSP,15PSP)\% epoxy composite
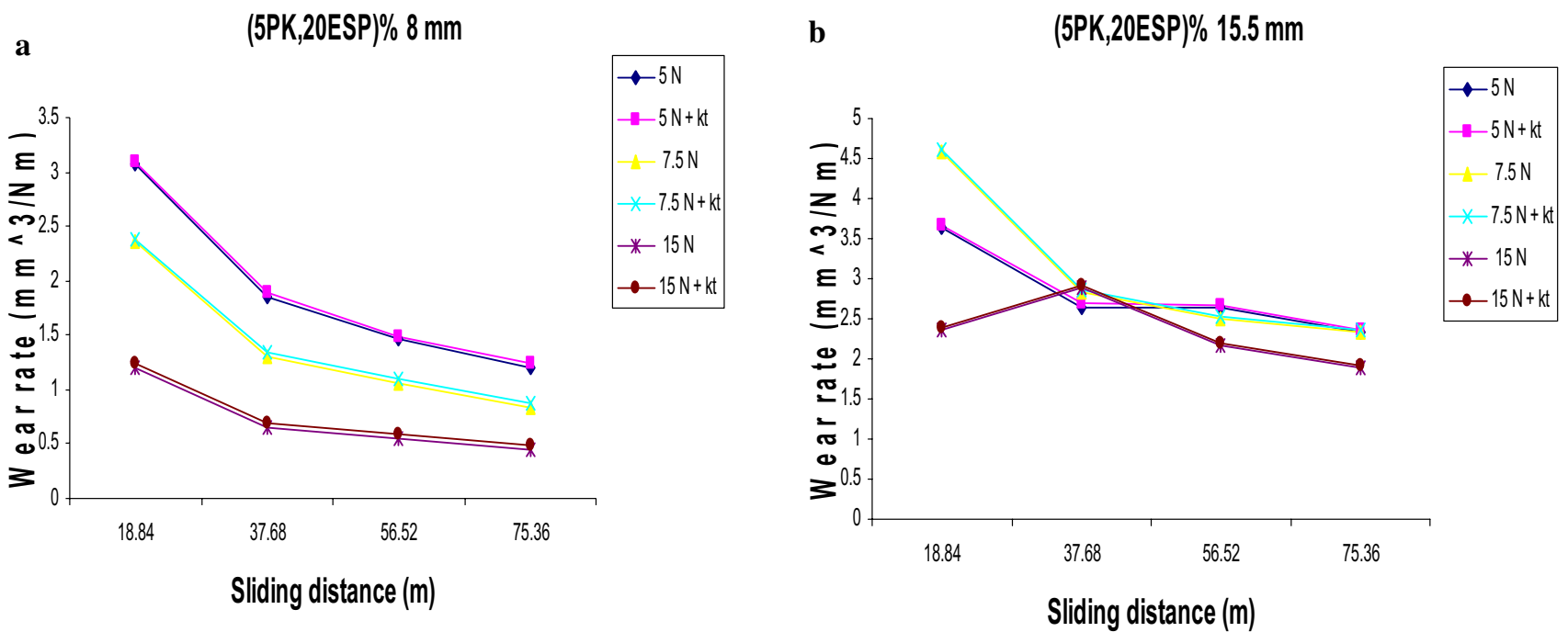

Fig. 12 Effect of OC on the SWR of (5PK,20ESP)\% epoxy composite. a Effect of opportunity cost on the wear rates of 8 mm (5PK,20ESP)\% epoxy composite. $\mathbf{b}$ Effect of opportunity cost on the wear rates of $15.5 \mathrm{~mm}$ (5PK,20EKSP)\% epoxy composite

respectively. The $15.5 \mathrm{~mm}$ sample experienced the largest wear rate of $3.83 \mathrm{~mm}^{3} / \mathrm{Nm}$ under the application of $5 \mathrm{~N}$ load and $18.84 \mathrm{~m}$ sliding distance.

The combined effects of the wear rate, inflationary factor and opportunity cost on the wear behaviour of the (10OP, 15PSP)\% composite are described in Fig. 17. The 8, 10,12 and $15.5 \mathrm{~mm}$ samples had a percentage increase of $148.04,147.97,147.24$ and $147.14 \%$ percentage increases in wear rate, respectively. The highest wear rate was obtained as $7.4 \mathrm{~mm} 3 / \mathrm{Nm}$ with the $15.5 \mathrm{~mm}$ sample under an applied load of $5 \mathrm{~N}$.

Figure 18 describes the influence of the wear rate, inflationary factor and opportunity cost model on the (5PK, 20ESP)\% composite. The percentage increases were recorded as $151.15,146.75,226.45$ and $144.91 \%$ for the $8,10,12$ and $15.5 \mathrm{~mm}$ samples, respectively. The $15.5 \mathrm{~mm}$ produced the highest wear rate of $11.22 \mathrm{~mm}^{3} /$ $\mathrm{Nm}$. However with a higher applied of $7.5 \mathrm{~N}$. 
(Brake pad) $15.5 \mathrm{~mm}$

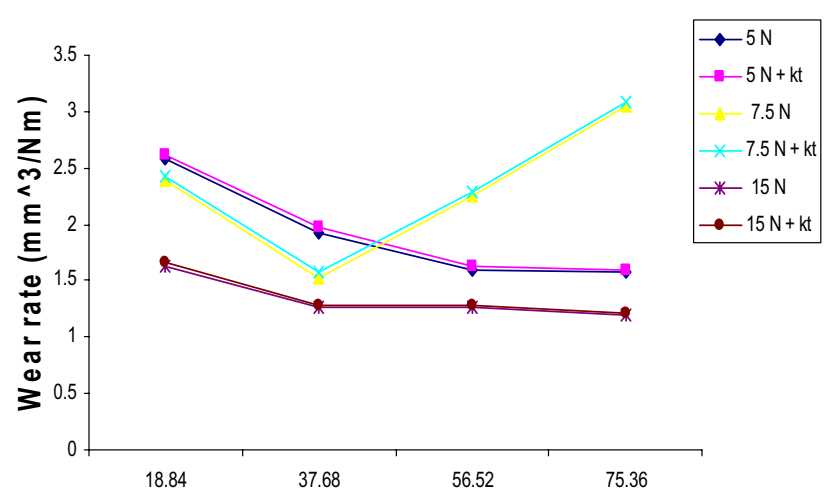

Fig. 13 Effect of OC on the SWR of brake pad sample

The influence of the wear rate, inflationary factor and opportunity cost model on the brake pad sample is described in Fig. 19. The highest wear rate was obtained by the brake pad sample as $7.22 \mathrm{~mm}^{3} / \mathrm{Nm}$ under a load application of $7.5 \mathrm{~N}$.

\subsubsection{Comparison with existing reports from the literature}

In an investigation carried out by Srinivas and Bhagyasheka [53], where graphite and silicon carbide were used as reinforcement in 10, 20, 30 and $40 \%$ filled epoxy composites. The highest wear rates from their work were by the $10,20,30$ and $40 \%$ filled composites were $6.82,6.24,3.91$ and $3.1610^{-5} \mathrm{~mm}^{3} / \mathrm{Nm}$ under the application of $10 \mathrm{~N}$. This is comparatively higher than the highest wear rates from the (10OP,15CSP)\%, (10PK, 15 CSP)\%, (10PSP, 15 ESP)\%, (10OP,15PSP)\% and (5PK,20ESP)\% epoxy composites in this work obtained as $1.76,2.14,1.37,3.02,3.07 \mathrm{~mm}^{3} / \mathrm{Nm}$, respectively, under the application of $5 \mathrm{~N}$. The same composites also obtained the highest wear rates of $1.05,1.13$, $1.01,1.4$ and $2.36 \mathrm{~mm}^{3} / \mathrm{Nm}$ under an applied load of $15 \mathrm{~N}$, which could still be considered better than the composites used by Srinivas and Bhagyasheka [53] in terms of wear resistance.

Although Srinivas and Bhagyasheka [53] used silicon carbide and graphite up to $40 \mathrm{wt}$. \% as reinforcement over longer sliding distances, the current work was restricted to $25 \mathrm{wt}$. \% of selected agro-wastes fillers. Further, the behaviour of the composites in the current investigation showed that wear rates decreased with increasing sliding distance and higher applied loads which correlate with Srinivas and Bhagyasheka [53]'s work. In another work, Agarwal et al. [54] used silicon carbide and chopped glass fibre to reinforce epoxy composites. The specific wear rates increased with higher applied loads up to $80 \mathrm{~N}$. They also discovered that the specific wear rate decrease with higher sliding velocity. This was attributed to the fact that at the higher sliding velocity the frequency of surface contact between the abrasive rubber wheel and the specimen reduces, hence the decrease in the value of the wear rates. Although the highest wear rates reported by Agarwal et al's [54] was around $0.04 \mathrm{~mm}^{3} / \mathrm{Nm}$, the high sliding speed range of $40-160 \mathrm{~cm} / \mathrm{s}$ which is about $4-16 \mathrm{~m} / \mathrm{s}$ can be said to be responsible. Comparatively, this investigation used a uniform sliding velocity of $0.314 \mathrm{~m} / \mathrm{s}$ to enable a

$(100 P, 15 C S P) \% 8 \mathrm{~mm}$

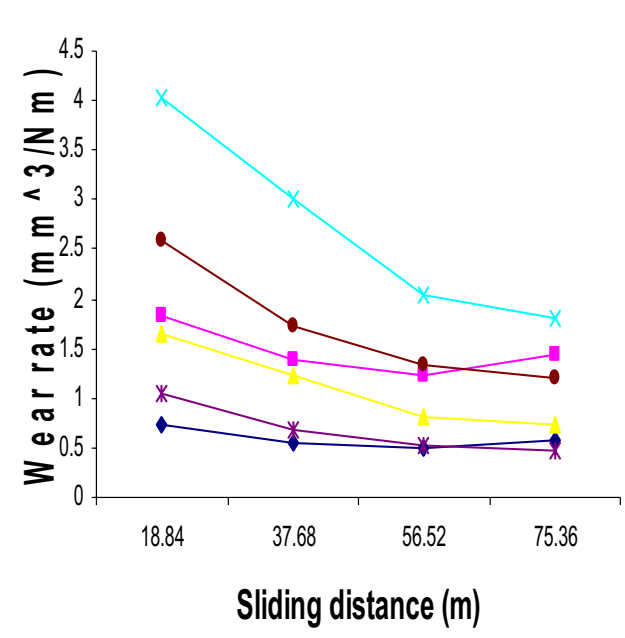

b

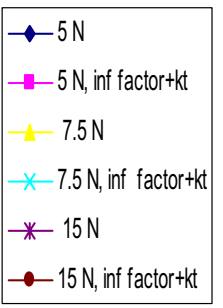

Fig. 14 The combined effect of IF and OC on the WR of (10OP,15CSP)\% epoxy composite. a Effect of IF and OC on the WR of 8 mm $(10 \mathrm{OP}, 15 \mathrm{CSP}) \%$ epoxy composite. $\mathbf{b}$ Effect of IF and OC on the WR of $15.5 \mathrm{~mm}(10 \mathrm{OP}, 15 \mathrm{CSP}) \%$ epoxy composite

\section{SN Applied Sciences}


a $\quad(10 \mathrm{PK}, 15 \mathrm{CSP}) \% 8 \mathrm{~mm}$

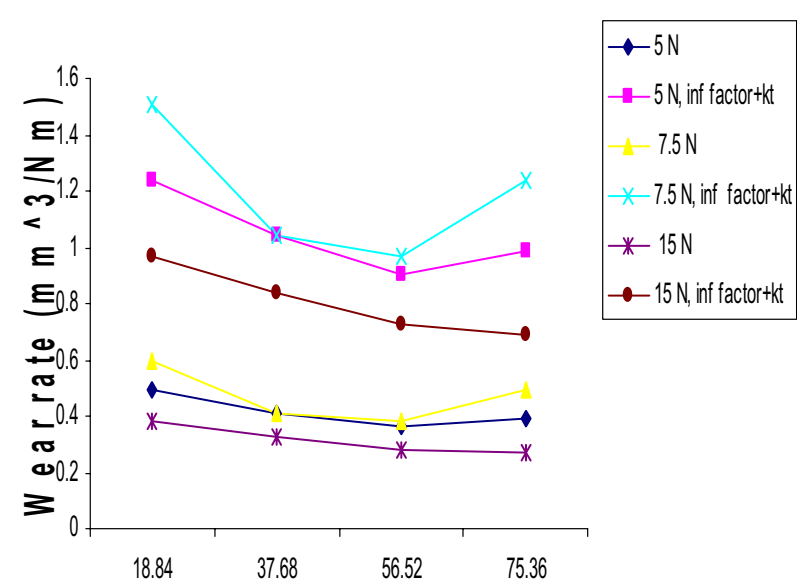

Sliding distance (m) b

(10PK,15CSP)\% $15.5 \mathrm{~mm}$

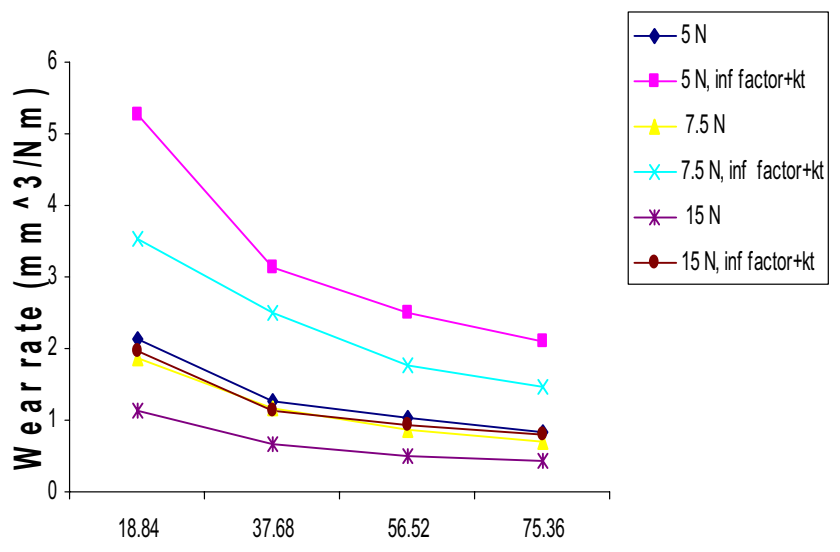

Sliding distance $(\mathrm{m})$
Fig. 15 The combined effect of IF and OC on the WR of (10PK, $15 \mathrm{CSP}) \%$ epoxy composite. a Effect of inflationary factor and opportunity cost on the wear rates of $8 \mathrm{~mm}$ (10PK,15CSP)\% epoxy composite. $\mathbf{b}$ Effect of inflationary factor and opportunity cost on the wear rates of $15.5 \mathrm{~mm}$ (10PK,15CSP)\% epoxy composite

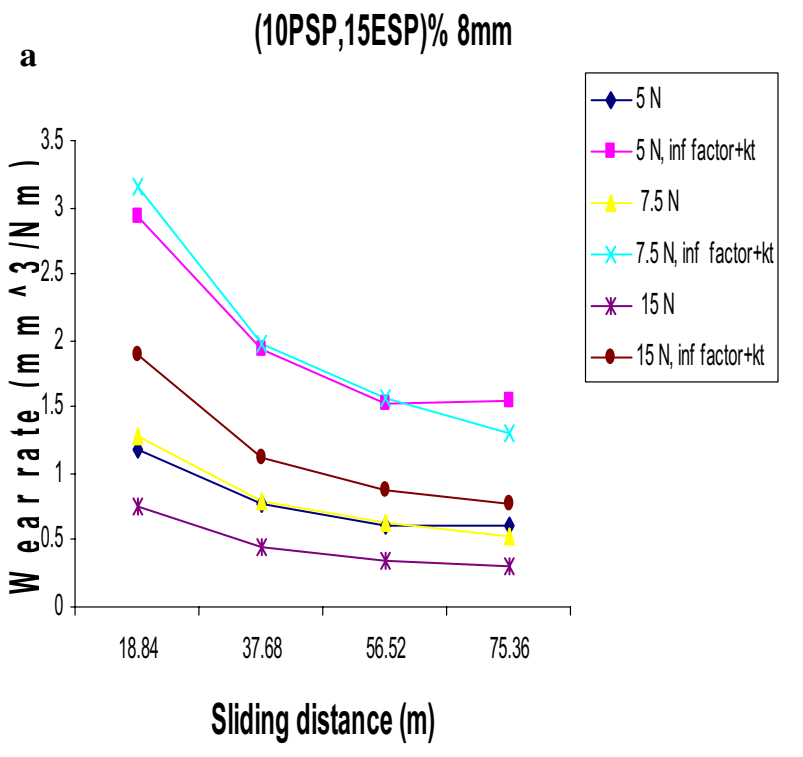

Fig. 16 The combined effect of IF and OC on the WR of (10PSP, $15 \mathrm{ESP}) \%$ epoxy composite. a Effect of inflationary factor and opportunity cost on the wear rates of $8 \mathrm{~mm}$ (10PSP,15ESP)\%

frequent surface contact between the abrasive cylindrical disk and the wear specimens.

The application of the inflationary factor, the opportunity cost on the wear rate of the composites and brake pads is a novel attempt to predict the expected wear rates of composites on a real-life basis. Although reports on this application are scarce in the literature, the obtained results are within acceptable limits when

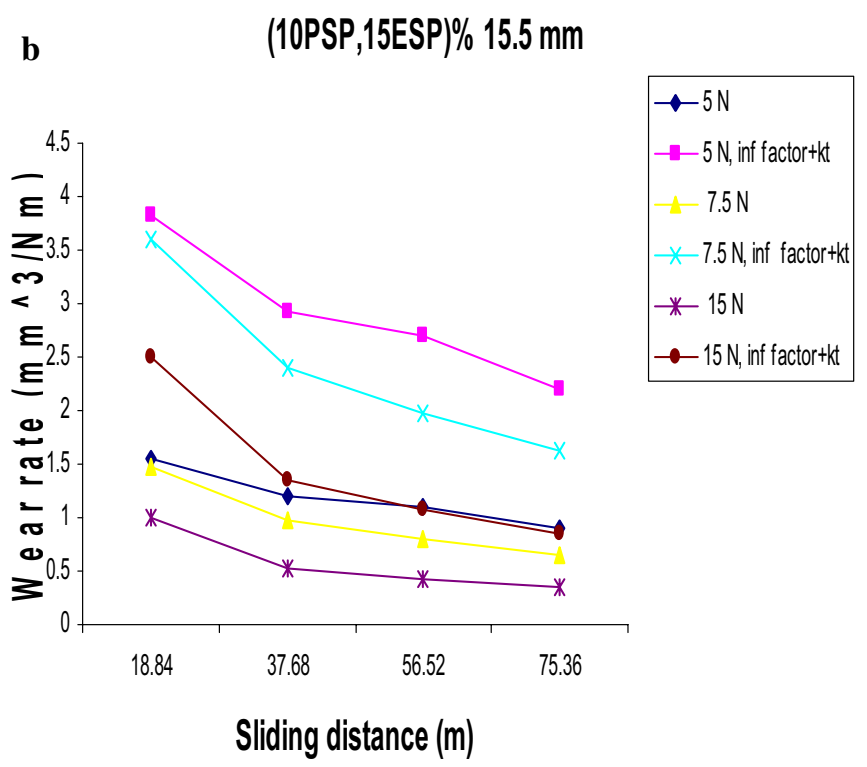

epoxy composite. $\mathbf{b}$ Effect of IF and OC on the WR of $15.5 \mathrm{~mm}$ (10PSP,15ESP)\% epoxy composite

compared with the work of Srinivas and Bhagyasheka [46]. In making the work relevant to the literature on composites, density was compared with literature values. As was found out in the literature, in the wide application area of brake pads, the notable research conducted by Keskin [20] where rice straw was used as single filler for composites could be compared with the current work. For the obtained composite in Keskin 


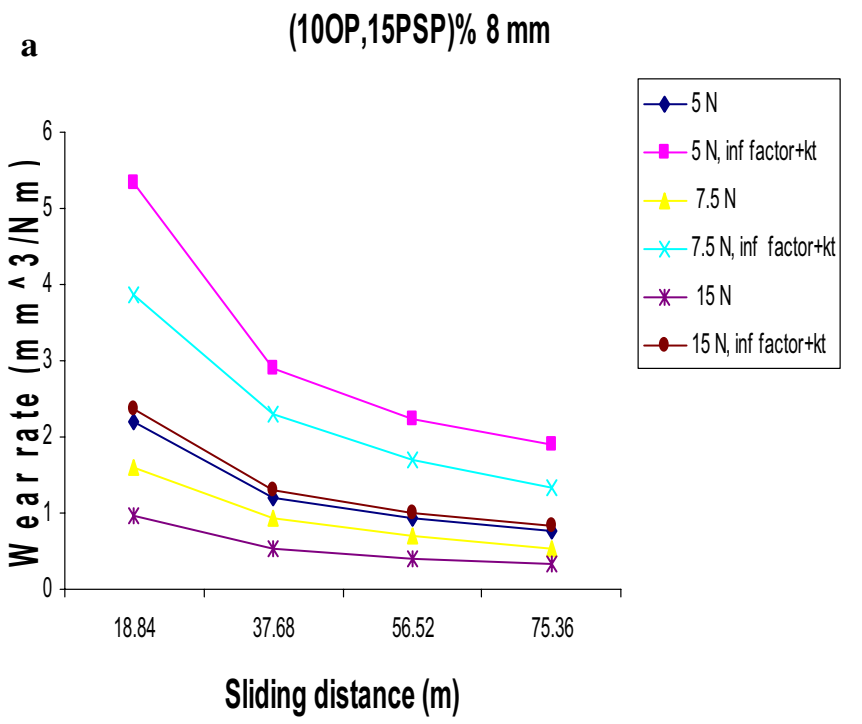

Fig. 17 The combined effect of inflationary factor and opportunity cost on the wear rate of (10OP,15PSP)\% epoxy composite. a Effect of inflationary factor and opportunity cost on the wear rates of

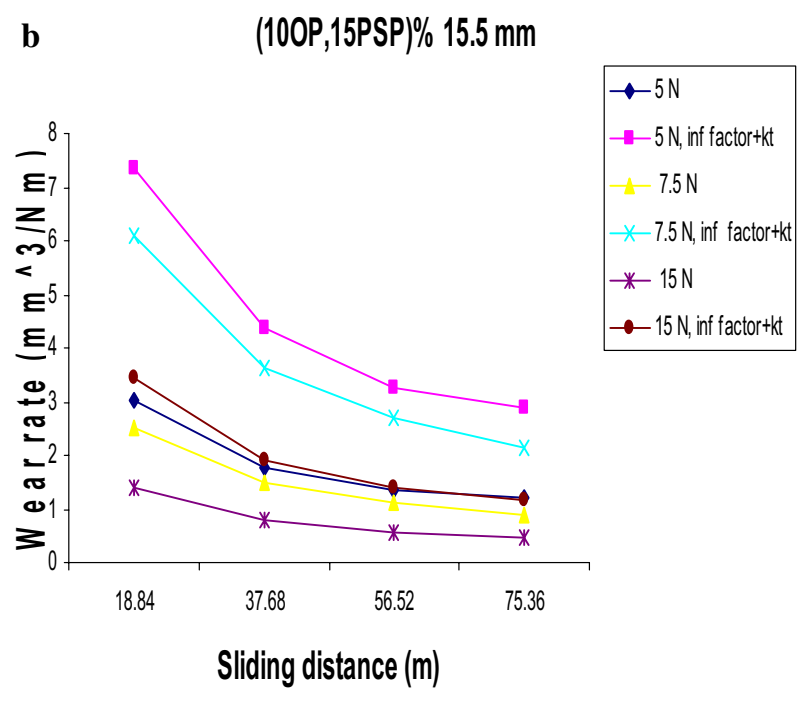

$8 \mathrm{~mm}(10 \mathrm{OP}, 15 \mathrm{PSP}) \%$ epoxy composite. $\mathbf{b}$ Effect of IF and OC on the WR of $15.5 \mathrm{~mm}$ (10OP,15PSP)\% epoxy composite

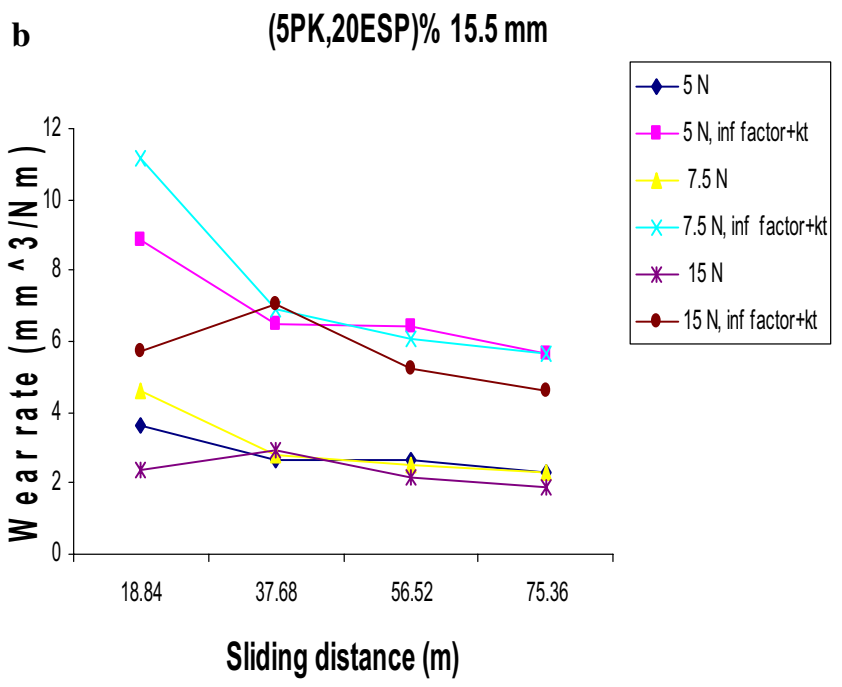

Fig. 18 The combined effect of IF and OC on the WR of (10PK,15ESP)\% epoxy composite. a Effect of IF and OC on the WR of 8 mm (5PK,15ESP)\% epoxy composite. b Effect of IF and OC on the WR of $15.5 \mathrm{~mm}$ (5PK,15ESP)\% epoxy composite

[20], the range of density obtained was $1.135-1.746 \mathrm{~g} /$ $\mathrm{cm}^{3}$, resulting in an average of $1.4405 \mathrm{~g} / \mathrm{cm}^{3}$. In the current research, the range of the five formulations was $1.141-1.288 \mathrm{~g} / \mathrm{cm}^{3}$, having an average of $1.2145 \mathrm{~g} / \mathrm{cm}^{3}$. In comparison, the results from the current work obtain less dense sets of specimens, aligning with the lightweight drive desirable in composite fabrication. It has a $15.69 \%$ less dense advantage, and this strengthens our intention of producing better composite outputs using mixtures of two reinforcements at a time instead of one. Consequently, it could be concluded that our agricultural based composites are better than rice strawbased composites performance.

\section{Conclusions}

In this paper, the wear rate is modelled to account for the inflationary cost of materials for cost-effective decisions, design optimization and to reduce the cost of producing composites. The following conclusions were drawn from the study: 
Fig. 19 The combined effect of OC on the SWR of brake pad sample
(Brake pad) $15.5 \mathrm{~mm}$

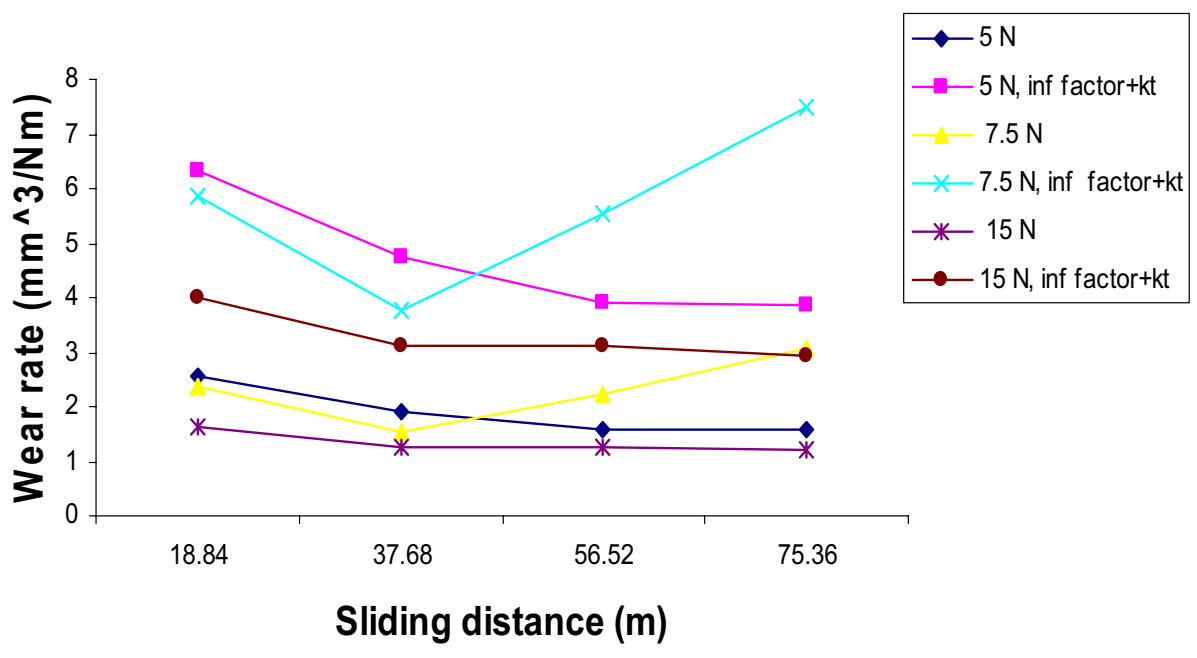

1. The obtained wear rate model accurately predicts the wear rate of the brake pad based on inflationary cost and opportunity cost. Moreover, the pseudo wear rate model predicts the impact of the independent variable i.e. inflationary cost, opportunity cost, time, and sample size.

2. The new wear rate model is very efficient and capable of estimating the wear response of the brake pad without underestimating the values. Therefore, the model is feasible for use in the design of brake pads. Moreover, this study can be a reference point for other products of the automobile such as the brake shoe.

3. The validation of the model was tested with practical results from laboratory experiments, which confirmed the workability of the model.

4. The model aid in reducing the cost of producing composites as it builds in inflationary cost thus bring in cost-consciousness into every worker in the production of composites

5. The use of dual agro-filler is better than single filler as the complementary properties of the constituent fillers are taken advantage of in a combined form as dual fillers than single filler.

The main advantage of dual filler is that the properties of the fillers complement each other. The orange peel particulate is one of the fillers used in this work and has lubricating advantages. It permits enhancement of the lubricating potentials and the tribological properties of the composite. This has a complementary advantage together with the properties of the second filler.
For future work, the following may be pursued. First, effort should be invested to enhance the model to incorporate mode details such as the interest rate for more accurate predictions of the wear rate of composites. Second, binding materials may be introduced between the filler to know their possible effects on wear rates of composites. Future efforts should consider adding a binder such as the pure water sachet [8] and cement [35]. This may improve the wear response of the developed composite.

Funding This study was not funded by any grant.

\section{Compliance with ethical standards}

Conflict of interest The authors declare that they have no conflict of interest.

Open Access This article is licensed under a Creative Commons Attribution 4.0 International License, which permits use, sharing, adaptation, distribution and reproduction in any medium or format, as long as you give appropriate credit to the original author(s) and the source, provide a link to the Creative Commons licence, and indicate if changes were made. The images or other third party material in this article are included in the article's Creative Commons licence, unless indicated otherwise in a credit line to the material. If material is not included in the article's Creative Commons licence and your intended use is not permitted by statutory regulation or exceeds the permitted use, you will need to obtain permission directly from the copyright holder. To view a copy of this licence, visit http://creativecommons. org/licenses/by/4.0/. 


\section{References}

1. Wimmer T, Huffmann AMS, Eichberger M, Schmidlin PR, Stawarczyk B (2016) Two-body wear rate of PEEK, CAD/CAM resin composite and PMMA: effect of specimen geometries, antagonist materials and test set-up configuration. Dent Mater 32(6):e127-e136

2. Pany J, Barik RK, Sahoo SK, Patnaik SC, Majhi J, Pattnaik AB (2020) Mathematical modelling for the prediction of wear rate of Al-12.6Si/TiB2 in situ composites. Mater Today. https://doi. org/10.1016/j.matpr.2020.03.493

3. Pasha SS, Imran M, Harish SN (2020) Wear rate and hardness characteristics of Al7075/kyanite $\left(\mathrm{Al}_{2} \mathrm{SiO}_{5}\right)$ composites. Today, In press, Mater

4. Huang L, Jiang S, Wang S, Zhang R, Sun F, Moridi A, Geng L (2020) Wear rate of titanium matrix composite coating at high temperature further increased by non-stoichiometric TixC oxidation. Ceram Int 46(6):8068-8074

5. Zhang HX, Dai JJ, Sun CX, Li SY, Zhang HL, Yu HJ, Chen CZ (2019) Wear rate and thermal conductivity of a copper-plated graphite flake/aluminum composite. J Electr Mater 48:7585-7592

6. Schramm G (1969) Relative price changes and the benefits and costs of alternative power projects. Ann Regional Sci 3:27-46

7. Leijonhufvud $A$ (1977) Costs and consequences of inflation. In: Harcourt GC (ed) The Microeconomic foundations of macroeconomics other international economic association publications series. Palgrave Macmillan, London

8. Turner MS (1988) Toward the inflationary paradigm lectures on inflationary cosmology. In: Galeotti P, Schramm DN (eds) Gauge theory and the early universe NATO ASI series (Series C: Mathematical and Physical Sciences). Springer, Dordrecht

9. Pappu A, Pickering KL, Thakur VK (2019) Manufacturing and characterization of sustainable hybrid composites using sisal and hemp fibres as reinforcement of poly (lactic acid) via injection moulding. Ind Crop Prod 137:260-269

10. Wang Z, Subramanian N, Gunasekaran A, Abdulrahman MD, Liu C (2015) Composite sustainable manufacturing practice and performance framework: Chinese auto-parts suppliers' perspective. Int J Prod Econ 170:219-233

11. Dutta T, Barman A, Majumdar G (2020) Green and sustainable manufacturing of metallic, ceramic and composite materials. Encyclo Renew Sustain Mater 3:474-486

12. Daguna IM, Ibhadode AOA (2006) Determination of optimum manufacturing conditions for asbestos-free brake pad using Taguchi method. Niger J Eng Res Dev 5(4):1-8

13. Muthi I (2009) Investigation of tribological properties of brake pads using rice straw and rice husk dust. J Appl Sci 9:377-381

14. Aigbodion VS, Akaide U, Hassan SB, Asuke F, Agunsoye JO (2010) Development of asbestos free brake pad using bagasse. Tribo Ind 32(1):12-18

15. Edokpia RO, Aigbodion VS, Atunranya CV, Agunsoye JO (2015) Mu'azuk (2015) Experimental study of the properties of brake pad using egg shell particles-gum arabic composites. J ChinAdv Mater Soc 10(1080/22243682): 1100523

16. Idris UD, Aigbodion VS, Abubakar IJ, Nwoye CI (2015) Ecofriendly asbestos free brake-pad: using banana peels. J King Saud Univ Eng Sci 27:3185-3192

17. Ghazali GMR, Kamarudin H, Jamaludin SB, AI-Baleri AMM, Liyana $J$ (2013) Mechanical properties and morphology of palm slag, calcium carbonate and dolomite filler in brake pad composites. Appl Mech Mater 313-314:174-178

18. Filip P, Kovarik L, Wright MA (1997) Automotive brake lining characterization, In, Proceedings of 15th Annual SAE Brake Colloqium, 319
19. Rinek LM, Cowen CW (1995) Passenger car brake history. Auto Eng 6:37-42

20. Keskin A (2011) Investigation of using natural zeolite in brake pad. Scient Res Essays 6(23):4893-4904

21. Libsch TA, Rhee SK (1978) Microstructural changes in semimetallic disc brake pads created by low temperature dynamometer testing. Wear 46(1):203-213

22. Mutiu I, Sugizu I, Keskin A (2015) The effects of porosity in friction performance of brake pad using waste tire dust. Polimeros. https://doi.org/10.1590/0104

23. Osterle W, Griepentrog M, Gross T, Urban I (2001) Chemical and microstructural changes induced by friction and wear of brakes. Wear 251:1469-1476

24. Maleque MA, Atiqah A, Talib RJ, Zahurin H (2012) New natural reinforced aluminum composite for automotive brake pad. Int J Mech Mater Eng 7(2):166-170

25. Sasaki Y (1995) Development philosophy of friction materials for automobile disc brakes. The Eight Inter Pacific Conf Auto Eng, Soc Auto Eng Japan, pp 407-412

26. Wannik WB, Ayob AF, Syahrullail S, Masjuki HH, Ahmad MF (2012) The effect of boron friction modifier on the performance of brake pads. Int J Mech Mat Eng 7(1):31-35

27. Wannik WB, Ayob AF, Syahrullail S, Masjuki HH, Ahmad MF (2012) The effect of boron friction modifier on the performance of brake pads. Int J Mech Mater Eng 7(1):31-35

28. Lithayakumar M, Kumaran ST, Aravindan S (2013) Dry sliding friction and wear studies of fly ash reinforced AA-6351 metal matrix composites. Adv Tribo 2013:6. https://doi. org/10.1155/2013/365602

29. Sharma MD, Sehgal $R$ (2014) Experimental study of friction and wear characteristics of titanium alloy (Ti-6Al-4V) under lubricated sliding condition. Ind Lubr Tribol 66(2):174-183

30. Fu Z, Suo B, Yun R, Lu Y, Wang H, Qi S, Jiang S, Lu Y, Matejka V (2012) Development of eco-friendly brake friction composites containing flax fibers. J Reinf Plast Compos 31(10):681-689

31. Sugözü I, Mutlu I, Keskin A (2015) The effect of using heat treated ulexite and cashew in automotive friction materials. Mater Test 57(9):744-749. https://doi.org/10.3139/120.110781

32. Öktem H, Uygur İ, Akıncıoğlu G, Kır D, Karakaş H (2015) Evaluation of non-asbestos high performance brake pads produced with organic dusts. In: paper presented at the metal 2015. Brno, Czech Republic, June 3rd-5th

33. Rajmohan B, Arunachalam K, Sundarapandian G (2017) Predict the tribological properties on brake pad using coconut shell/ sugarcane/SiC powder hybrid composites. Int J Eng Innov Tech 7(3):43-49. https://doi.org/10.17605/OSF.IO/2BH9D

34. Akıncıoğlu G, Öktem H, Uygur I, Akıncıoğlu S (2018) Determination of friction-wear performance and properties of eco-friendly brake pads reinforced with hazelnut shell and boron dusts. Arab J Sci Eng 43:4727-4737. https://doi.org/10.1007/s1336 9-018-3067-8

35. Olumodeji JO (2013) Assessment of agricultural waste for production of brake pads. Int J Eng Res Technol 2(11):4070-4079

36. Ademoh NA, Olabisi Al (2015) Development and evaluation of maize husks (asbestos-free) based brake pad. Ind Eng Lett 5(2):67-80

37. Olabisi Al, Adam AN (2016) Okechukwu OM (2016) Development and assessment of composite brake pad using pulverized cocoa beans shells filler. Int J Mater Sci Appl 5(2):66-78. https://doi. org/10.11648/j.ijmsa.20160502.16

38. Yawas DS, Aku SY, Amaren SG (2016) Morphology and properties of periwinkle shell asbestos-free brake pad. J King Saud UniverEng Sci. https://doi.org/10.1016/j.jksues.2013.11.002 
39. Ahmed AO, Umar A, Aliyu BU, Omilabu EB, Khalifa SY (2018) Development of asbestos free-brake pad using solid waste. ATBU J Sci Tech Edu 6(2):121-126

40. Achebe $\mathrm{CH}$, Chukwuneke JL, Anene FA, Ewulonu CM (2019) A retrofit for asbestos-based brake pad employing palm kernel fiber as the base filler material. P I Mech Eng L-J Mat 233(9):1721-1732

41. Akıncıoğlu G, Akıncıoğlu S, Öktem H (2020) Uygur I (2020) Wear response of non-asbestos brake pad composites reinforced with walnut shell dust. J Aust Ceram Soc. https://doi.org/10.1007/ s41779-020-00452-6

42. Adeyemi IO, Nuhu AA, Thankgod EB (2016) Development of asbestos-free automotive brake pad using ternary agro-waste fillers. J Multidiscip Eng Sci Technol 3(7):5307-5323

43. Masturi M, Effendy S, Gelu A, Hammam H, Fianti F (2018) Analysis of the mechanical properties brake canvas with basic ingredients of the durian fruit skin and teak leaves. Jurnal Bahan Alam Terbarukan 7(2):149-155

44. Uzochukwu MI, Aiyejagbara MO, Ugbaja MI (2019) Property investigation of cowhorn/prewrinkle shell epoxy composite for automobile brake pad linings. J Emerg Trend Eng Appl Sci 10(2):48-53

45. Yilmaz EC (2020) Effect of contact load upon attrition-corrosion wear behavior of bio-composite materials: In vitro off-axis sliding contact-chewing simulation. Biomed Res J 7:17-22

46. Sharma V, Meena ML, Kumar M, Patnaik A (2020) Mechanical and three-body abrasive wear behavior analysis of glass and basalt fiber-reinforced epoxy composites. Polym Compos 41(9):3717-3731

47. Erturk AT, Vatansever F (2020) Abrasive wear performance of multi-layer interwoven polyester fiber and PTFE particle reinforced polyester composite. J Compos Mater 54(28):4415-4425
48. Kruzic JJ, Arsecularatne JA, Tanaka CB, Hoffman MJ, Cesar PF (2018) Recent advances in understanding the fatigue and wear behavior of dental composites and ceramics. J Mech Behav Biomed Mater 88:504-533

49. Tsujimoto A, Barkmeier WW, Fischer NG, Nojiri K, Nagura $Y$, Takamizawa T, Latta MA, Miazaki M (2018) Wear of resin composites: current insights into underlying mechanisms, evaluation methods and influential factors. Jpn Dent Sci Rev 54(2):76-87

50. Kumar R, Dwivedi RK, Ahmed S (2019) Wear characteristics and temperature analysis of alloy steel using self-developed wear testing machine. Mater Today 18(7):2875-2880

51. Allebert J, Jungedal $M$, Waara $P$ (2015) Wear on overlay welded $\mathrm{HCWI}$ vs. quenched and tempered low alloyed carbon steels evaluated with granite in a laboratory drum test machine. Wear 330-331:364-370

52. Shehab E, Ma W, Wasim A (2012) Manufacturing cost modelling for aerospace composite applications, The 19th ISPE int conf concur eng-CE2012At: trier (Germany), https://doi. org/10.1007/978-1-4471-4426-7-37

53. Srinivas K, Bhagyasheka MS (2014) Wear behaviour of epoxy hybrid particulate composites. Procedia Eng 97:488-494

54. Agarwal G, Patnaik A, Sharma RK (2013) Parametric optimization and three-body abrasive wear behaviour of SiC filled chopped glass fiber reinforced epoxy composites. Int J Comp Mater $3(2): 32-38$

Publisher's Note Springer Nature remains neutral with regard to jurisdictional claims in published maps and institutional affiliations. 